Article

\title{
On How Technology-Powered Storytelling Can Contribute to Cultural Heritage Sustainability across Multiple Venues-Evidence from the CrossCult H2020 Project
}

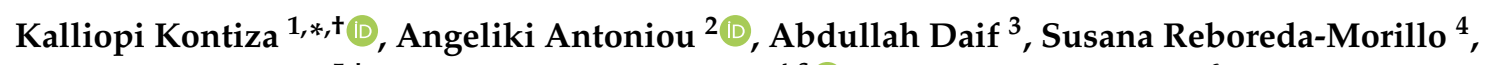

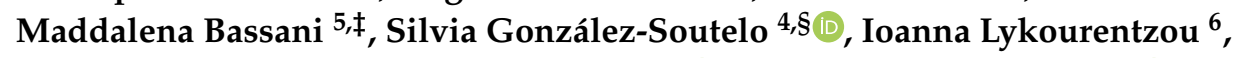 \\ Catherine Emma Jones ${ }^{7}$, Joseph Padfield ${ }^{8}$ (D) and Martín López-Nores ${ }^{3}$ (D) \\ 1 Former CrossCult Fellow, Research Department, The National Gallery, London WC2N 5DN, UK \\ 2 Department of Informatics and Telecommunications, University of the Peloponnese, 22100 Tripoli, Greece; \\ angelant@uop.gr \\ 3 AtlantTIC Research Center, Department of Telematics Engineering, University of Vigo, 36310 Vigo, Spain; \\ adrady@det.uvigo.es (A.D.); mlnores@det.uvigo.es (M.L.-N.) \\ 4 Group of Studies in Archaeology, Antiquity and Territory, University of Vigo, 32004 Ourense, Spain; \\ rmorillo@uvigo.es (S.R.-M.); silvia.gonzalezs@uam.es (S.G.-S.) \\ 5 Dipartamento dei Beni Culturali, Università Degli Studi di Padova, 35122 Padova, Italy; \\ maddalena.bassani@unipd.it \\ 6 Department of Information and Computing Sciences, Faculty of Science, Utrecht University, \\ 3584 CC Utrecht, The Netherlands; i.lykourentzou@uu.nl \\ 7 Faculty of Language and Literature, Humanities, Arts and Education, University of Luxembourg, \\ L-4365 Esch-sur-Alzette, Luxembourg; catherine.jones@uni.lu \\ 8 Research Department, The National Gallery, London WC2N 5DN, UK; Joseph.Padfield@ng-london.org.uk \\ * Correspondence: k.kontiza.12@ucl.ac.uk \\ † Current address: Department of Information Studies, University College London, Gower Street, \\ London WC1E 6BT, UK. \\ † Current address: Study Center classicA, Università Iuav di Venezia, 30135 Venice, Italy. \\ $\S$ Current address: Department of Prehistory and Archaeology, Universidad Autónoma de Madrid/MIAS, \\ 28049 Madrid, Spain.
}

Received: 17 January 2020; Accepted: 9 February 2020; Published: 23 February 2020

check for updates

\begin{abstract}
Sustainability in Cultural Heritage $(\mathrm{CH})$ is a complex question that needs to be addressed by a group of experts tackling the different issues. In this light, the present work wishes to provide a multi-level analysis of the sustainability in $\mathrm{CH}$, using as an example a recent European $\mathrm{H} 2020$ project (CrossCult) and the lessons learnt from its design, implementation and evaluation. The sustainability of $\mathrm{CH}$ has qualitatively changed over the last few years, under the developments in digital technology that seems to affect the very nature of the cultural experience. We discuss sustainability in venues using digital technologies, covering a span of needs of small/unknown and large/popular venues, which try to enhance the visitor experience, attract visitors, form venue networks, etc. Moreover, we explore issues of sustainability of digital content and its re usability through holistic design. Aspects of technology, human networks and data sustainability are also presented, and we conclude with the arguments concerning the sustainability of visitor reflection, the interpretation of social and historical phenomena and the creation of meaning.
\end{abstract}

Keywords: cultural heritage; sustainability; storytelling; digital humanities 
"Every visitor interaction is a story-making as visitors fit portions of our collections into personal frames of reference; most often in ways we neither intended nor anticipated."

R.R. Archibald [1]

\section{Sustainability through Cultural Heritage}

According to the Council of Europe's Framework Convention on the Value of Cultural Heritage for Society (held in 2006 in Faro, Portugal), Cultural Heritage (CH) may be defined as "a group of resources inherited from the past which people identify, independently of ownership, as a reflection and expression of their constantly evolving values, beliefs, knowledge and traditions". The European Expert Network on Culture extended that definition with a notion of 'heritage sector' constituted by specialised activities involving heritage and related to other social or economic sectors, which provides jobs and generates growth. That direct impact is augmented by the social and economic effects of $\mathrm{CH}$ in other fields, such as agriculture, regional development, environment, science and education, tourism, technology, innovation, social cohesion, intercultural dialogue, etc [2].

The aforementioned implications have been highlighted by numerous scientific studies, to the point that many policymakers now consider $\mathrm{CH}$ as one of the four pillars of sustainable development [3]. It contributes to sustainable growth through "a creative combination of the legacy of the past with innovative ideas aimed at shaping the future", raising the profiles of places to make them more competitive in a globalised world, and serving as a source of inspiration for the contemporary arts and creative industries [4]. However, the sustainability of $\mathrm{CH}$ itself is being jeopardised whenever one of the following two opposites is reached:

- On the one hand, the pressure exerted on popular museums, buildings, archaeological sites or historical city centres (e.g., as a consequence of mass tourism) poses growing challenges to heritage professionals, institutions and stakeholders to protect and enhance the cultural assets as well as the territory around them. In the era of mobile devices, social media and massive consumption of information (quick and shallow reading, limited reflection), popular exhibits even face the risk of being deprived of their meaning, becoming ornamental stuff for casual photographs or suffering de-essentialising cultural appropriation [5].

- On the other hand, the lesser-known heritage-which is widespread-oftentimes incurs significant management and preservation costs for the benefit of reduced numbers of residents or visitors. In many cases, especially for the intangible heritage of social minorities, the levels of awareness and visibility are very low, and there are increasing risks that the heritage will be lost in a matter of a few years or decades. Practical loss may still happen if the heritage has been captured in digital form, but it remains in isolated and unconnected archives.

During the last decades, Information and Communication Technologies (ICTs) have altered the ways in which $\mathrm{CH}$ information can be gathered from, managed by and delivered to residents, tourists, businesses, Humanities experts and policymakers. In this paper, we describe how some of the recent advances can contribute to $\mathrm{CH}$ sustainability -to both alleviate the pressure on the popular assets/venues and increase the preservation and valorisation of the lesser-known ones-by empowering the aforementioned stakeholder groups in different ways. Specifically, we present evidence gathered during the $\mathrm{H} 2020$ project CrossCult (www.crosscult.eu) about how technology-powered storytelling can contribute to the sustainability of the heritage kept by museums (in different ways depending on their size, popularity and topics) by presenting historical knowledge, interrelated facts and events, interpretations and narratives across countries and cultures to non-specialist audiences in an engaging way. The project can be considered a representative of the state-of-the-art, as it dealt with semantic reasoning technologies [6] to bring together multiple exhibits according to different criteria, with personalisation and recommendation systems to address the personal context that the museum visitors bring with them [7], with different storytelling and 
gamification strategies to assess the value of playful elements towards reflection and engagement with the venues and exhibitions [8,9], with location tracking and path routing optimisation to ensure that each visitor were navigated through the conceptually-linked exhibits while avoiding congested spaces as much as possible [10], and with innovative practices to address visitors' interaction with the physical context of the museum [11].

The Heritage venues participating in the project acted as demonstrators of these technologies and pilots for experimentation with visitors. Experiments took place in different Heritage venues of historical interest, meant to be representative of the different $\mathrm{CH}$ venues found across Europe in terms of their audience, needs, objectives and constraints:

- A vast transnational collection hosted at the National Gallery in London that wanted to invite visitors to explore conceptually linked exhibits that interest them the most.

- Four thematically similar archaeological sites (the Roman healing spa of Lugo in Spain, the Roman healing spa of Chaves in Portugal, the archaeological site of Montegrotto Terme in Italy, and the sanctuary of Epidaurus in Greece) that wanted to use narratives to connect their local heritage with other venues and broader European context.

- A small but invaluable collection hosted at the Archaeological Museum of Tripolis that aimed to present non typical itineraries through its museum exhibits.

- Two cities (Malta and Luxembourg City) connected through the topic of historical migration, that invite people to walk and serendipitously discover hidden stories or contribute their own.

In the following subsections, we explain how the aforementioned technologies touched different facets of $\mathrm{CH}$ sustainability, with examples from the project's pilot experiments. First, Section 2 looks at key aspects of sustainability within $\mathrm{CH}$ venues, from the big and most famous to the small and relatively unknown. Then, Section 3 discusses the sustainability of the different types of narratives delivered by the storytelling approaches, in relation to the effort and cost incurred by the content creation processes. Lastly, Section 4 focuses on sustainability within the $\mathrm{CH}$ ecosystem (ecosystem here is defined as all the 'living organisms' (data, objects, systems) and actors in a particular area $(\mathrm{CH})$ considered together with their physical environment (venue)): The technology itself, discussing the advantages enabled by the open source philosophy and the professional profiles demanded in Digital Humanities (DH), the actors and dynamic groupings (such as GLAM labs), highlighting their mediating role to facilitate external audience engagement and interaction with the (technology and data) $\mathrm{CH}$ system and finally the data that underpins the operation of the technology, considering the opportunities generated by the wealth of content digitised during the last decades, as well as the challenges derived from the different standards and reference models and from varying levels of reliability of the information sources.

\section{Sustainability within Venues}

Since Falk and Dierking published 'The Museum Experience' 20 years ago, most exhibitions and programs are designed with careful attention not only to aspects of the physical context (such as lighting, color, placement of objects, and readability of text) but also to the visitors' personal and socio-cultural contexts, which conform unique backgrounds of prior experiences, interests, knowledge, motivations, beliefs, and values. According to their suggested framework, "the museum experience begins before the visit to the venue, includes experiences within its premises (interactions with staff and members of one's own group, as well as with other visitors, exhibitions, interpretive materials and programs) and continues long after the visitor leaves" [12]. In order for technology to underpin sustainable visiting models, it must be able to reach those different stages and make the most of the users' time and attention, by providing them with the right kind of information. The CrossCult project approached this challenge in different ways within the multifaceted cultural venues involved, though always relying on storytelling strategies in order to ensure coherence of the end-to-end experiences and foster the intended cognitive phenomena. 


\subsection{Sustainability in Large Venues}

The first CrossCult use case took place at the National Gallery (NG) in London, visited by 5.7 million people in 2018 (visitor figure available through the Association of Leading Visitors Attraction (ALVA)—see https:/ / www.alva.org.uk/details.cfm?p=423) and well-aware of sustainability issues faced by a large venue. This section will focus on explaining how personalisation technologies and the stories behind recommended sets of pictures, addressed some of the venue sustainability challenges. The created CrossCult NG application aimed to sustain visitors physical interaction with the venue (wayfinding) and increase visitors knowledge and interest of an interconnected, multi-themed collection, of more than 2.600 paintings, that narrates the story of European art, masterpiece by masterpiece. The quotes presented in this section were collected during the last phase of evaluation for this venue that took place in June, August and December of 2018, where the think aloud protocol was used to capture participants' thoughts and experience [13]. We used a snowball method of recruiting participants-12 volunteers (10 female) with ages ranging from 30 to 65 -via the researchers' professional networks (art historians, heritage scientists, curators, other museum professionals). While the participants work at $\mathrm{CH}$ field only half of them had a good prior knowledge of the NG collection.

Once inside a large venue, there is often a high degree of freedom and choice in terms of what to look at, discuss, and do. It was the CrossCult vision that a bespoke mobile app could contribute to (i) encouraging visitors to think about topics that personally interested them, by connecting seemingly disparate paintings together, and (ii) the process of reflection, by encouraging visitors to connect trains of thought between the different paintings. Accordingly, the CrossCult NG (https:/ / play.google.com/ store/apps/details?id=eu.crosscult.pilot1.ng\&hl=en) app was created to guide the visitors through the NG collection, providing recommended short tours or highlighting individual paintings, based on a user's preferences, activities and physical location [14]. The application aimed to demonstrate that, by properly presenting curated sets of paintings, it is possible to (i) facilitate and promote the discovery and exploration of connections among the subjects depicted, the painters themselves, and events across the physical collection displayed over more than 69 galleries, and at the same time (ii) help visitors to access and navigate around the venue in a more balanced and dynamic way. The app detects the user's location in the building, takes into consideration visitors' tolerance to crowds and reduces the pressure on certain rooms by fostering greater interest for paintings other than the 'must-see masterpieces'.

The personalised NG app experience was designed to strengthen the engagement with the collection through the interaction with the app, before, during and after the visit. The engagement can be initiated at any point, even before the visitors' arrival to the Gallery building. By following a process of short steps, the visitors prepare and tailor their visit, by building a user initiated profile, which is then used by the app to recommend groups of paintings and stories. To accommodate the needs of visitors that are less confident or knowledgeable about art, instead of asking them direct questions about their favourite artist or art period, the app introduces them to the NG Collection with a carousel of paintings (see Figure 1a). This pre-curated set of paintings is used by the profiling system to build a first, a-priori profile. The user can stop this process at any time as the profiling algorithm needs only a minimum of 3 paintings to begin making recommendations on the whole collection. During the profiling process steps, the visitors could also (i) configure different settings such as the time available for the visit and whether they are alone or visiting in a group, (ii) see how far they have progressed during the carousel interaction and continue if they want to, (iii) further customise their profile by selecting their interests from a curated list of keywords and finally (iv) state how fast they walk when they visit a museum on average (see Figure 1b). While the user interacted with the app, by visiting rooms and specific paintings, the profile kept updating in the background. 


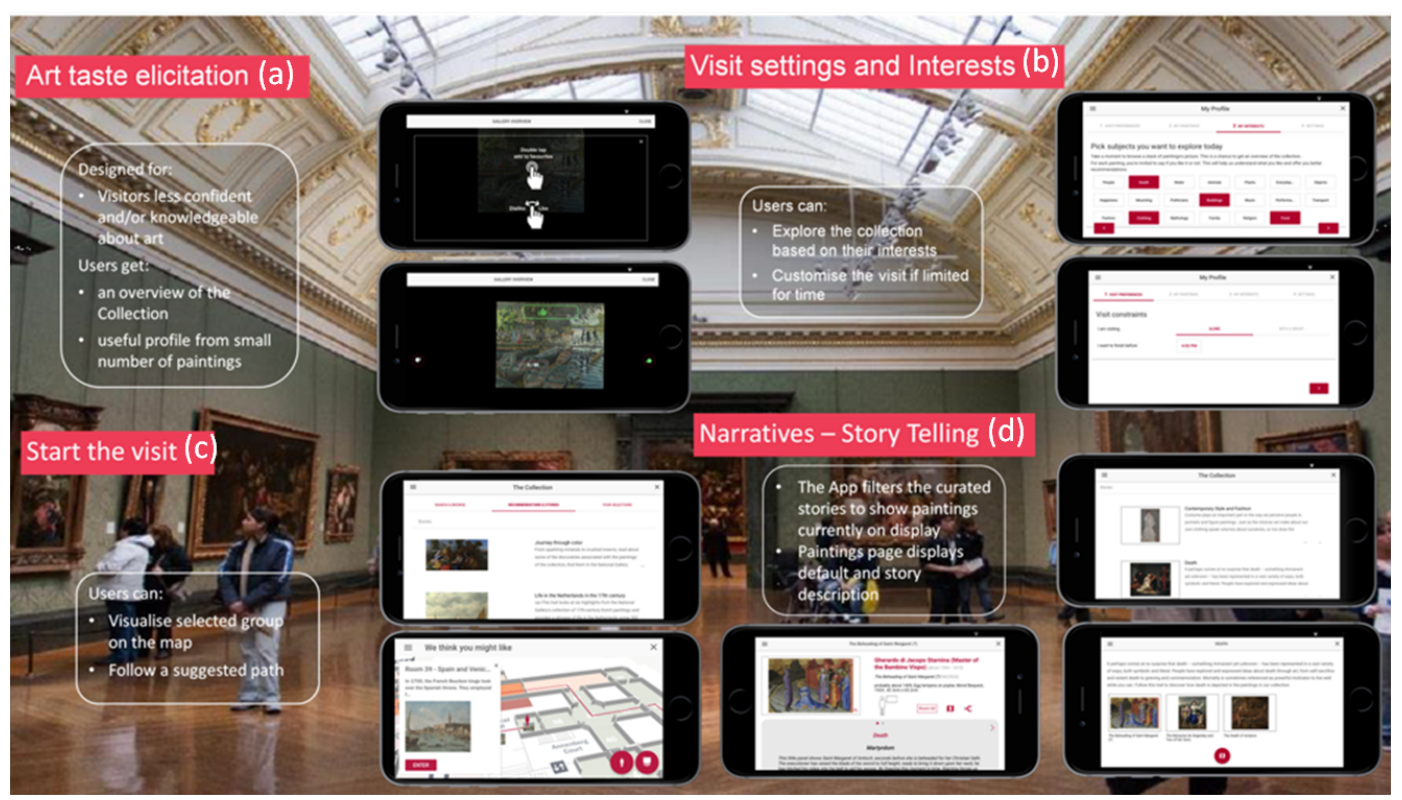

Figure 1. This Figure presents some highlighted features and functionalities of the National Gallery CrossCult app: (a) Top left hand corner, the 'Art taste elicitation' panel contains screenshots of the carousel of paintings: Users swipe right or left through a stack of images from the top 100 paintings of the NG Collection to indicate what they like or dislike. (b) top right hand corner, the 'Visits settings and Interests' panel contains screenshots of the settings configuration. (c) bottom left hand corner, the 'Start the Visit' panel contains screenshots of the app personalised recommendations presented to the user, once the profiling process was completed. By clicking on the map the visitors could access the current content of a Room, receiving fresh information from the Gallery's content management system through the NG research Beta API. (d) bottom left hand corner, the 'Narratives - Storytelling' panel contains screenshots of the app recommended pre-defined stories and narratives, under specific themes, to allow visitors to experience the collection through different lenses.

We observed that personalisation and profile building can be used as a technique to set the foundation of a relationship that can be built in time between the visitor and the $\mathrm{CH}$ venue and that, for the participants who were very familiar with the collection, the profiling process provoked a range of positive emotional reactions which were mainly associated with the act of new discovery. For example, P11 “While I am a person that knows what I like, it surprised me, some of the paintings I didn't know we had and [the carousel] showed me some of my favourite pictures, so...", P01 "This one I didn't realise we had it in the collection I haven't seen it before", P01 "it introduced me to a couple of things I didn't know which is great and you have a collection you think you are familiar with and shows you things you don't know about so that is interesting...". The connection of the visitors with the collection was initiated during the expressed reactions of liking or disliking a painting; the pre-curated sets of paintings, presented through the carousel of paintings strengthened the inter-connectivity of a multi-themed collection and the carousel interaction enabled the act of information and object discovery for some of the participants by giving them a new way into the collection. For some of the visitors this connection process enhanced their familiarity with the collection and sustained their intellectual journey of discovery, building at the same time future engagement with the $\mathrm{CH}$ venue and the collection. For example P01 "Animals, Saints, Furnitures, Boats so if you went for just one or more specific, that makes a lot of sense if they are affecting my paintings...I think the choices were limited but for this experience to give... you a way in to get into the collection it is quite nice... I should probably go and have a look at that too. This was connected to my choices... boats... I felt with this one putting in the parameters of what I was doing I was able to get information out of the app that I wanted and also in some cases looking for more information that perhaps was not there but it encouraged me to look around outside of the app and see things that I was not aware they were there." 
One of the main features of the CrossCult NG app experience, accessible before and during the physical visit, was the digital map. It promotes sustainability within the venue as a building by augmenting the familiarity of the visitors with the sense of place; it also allowed the visitors to pre-plan their visit, familiarise with the building and the different floors, and get a grasp of the Gallery size even before they arrive and maximise the limited time they might have available (see Figure 1c). Once the visitors were in the building, the app automatically detected their position, so that they could see where they were and ask for routing information to navigate from one room to the other. While visitors walked through the rooms, the app displays a preview of the content of the room they were currently in, a preview of the paintings currently on display. Visitors could also use the map to locate a painting within the Gallery and get indications on how to reach it.

While some of the participants in the evaluation had a good prior knowledge of the collection and the building, all of them stressed the difficulty of finding their way in the Gallery rooms. The difficulty to navigate through the physical space at the Gallery (wayfinding) and how the digital map with the automated indication of their current location supported them in making decisions on where to go, was highlighted; P01 "you can spend half an hour in Gallery and not have seen anything because you are looking around for something", P11 "ok so now I embark, so here I am trying to figure out which Room I am in, this was actually really good, it pretty much understood the Room I was in right away which was really useful because a few times I looked for Room numbers to match the Room numbers on the map but I couldn't find them on the Rooms", P12 "But then once that is there is so... it is so intuitive to... it is so nice having... when you are in a big Gallery, having a route and specific things to look at and to kind of narrow it down, something that it is going to direct you to specific things rather than just wander around".

With their location detected by the app, visitors could ask the app to display a route to visit a painting in a dynamic way and follow the proposed recommendations for a group of paintings on the digital map; the app detected the visitors location in the building and displayed a path for them to follow from their current location to the paintings location. If they decided to visit another room not indicated in the path, then the path dynamically updated. During this personalised discovery of information, objects and stories, either by following a path or diverting from it, the participants curiosity was sparked, which allowed them to reflect on prior learning and previous experience and fostered greater interest for new information discovery of not such well known paintings of the collection. For example, the recommended set of paintings while following the app's designated path P12 "sort of encouraged me to focus on things that I want, some things that I have taken for granted sometimes, so I managed to focus on different details and to look at things in a different way that I normally do" and on the recommended set of paintings while deviating from the app's designated path P11 "so that was really interesting because I wouldn't had stopped at this painting otherwise".

For venues that host well-known and highly-visited artworks in their collections, the breadth and scale of their visiting audiences varies from 'rebouncing' visitors that aim to contemplate with their favourite painting in quietness, to 'buzzing' crowds that visit for their first time Van Gogh's 'Sunflowers'. We have observed that the discovery of recommended groups of paintings lead participants to elaborate upon the connections between personal experiences and what they have read or noticed about the artworks. This part of their visiting experience also fostered their curiosity by encouraging discovery of other paintings either in the same room or in other less crowded rooms. For example P08 "I spotted something on the walk- and this is where I stopped it wasn't anything it was just a picture I was walking through it's just I wanted to discover a bit more about it and felt comfortable to come out [of the path] and learn a bit more about that painting then go back in the tour, so I would so for instance I would rather see less famous works where I could actually move around easily then to be in room so full as this where I can not enjoy them I can't it really wasn't a pleasant experience but I how would the app with know where all the people are? yes I would rather have gone to less famous if you like examples of pictures with colour obscure ones where there are few people then to be crowded like that which I found really irritatingly difficult". 
As a preamble to Section 3 where we discuss in more detail the sustainability of digital storytelling, we will briefly highlight here the relevance of the CrossCult NG stories for a large venue (see Figure 1, (d)). The NG had previously experimented with stories and narratives that visitors could print in advance and explore when they arrive. However because of their fixed format, they could not accommodate paintings' change of location as they were published as static resources in PDF format. In the CrossCult project, we explored the dynamic digital storytelling approach, taking into account the paintings change of location, that is rather crucial for a $\mathrm{CH}$ institution that needs to accommodate movement of paintings due to loans, conservation, in-house exhibitions etc. In addition to the pre-curated set of paintings for the carousel interaction that showcased the diversity and inter-connectivity of the collection, the app also recommended a second set of pre-defined stories and narratives, under specific themes; the CrossCult stories, a compilation of short descriptions for paintings, are grouped under a narrative that stems from a theme (i.e, Materials and Technique, Social Connections, Historical Events).

From the analysis of the participants' commentary on the reenactment of their visiting experience, it became more and more evident that the act of reading complementary alternative digital texts to the traditional descriptions, encourages a closer reading of the painting [13]. Storytelling and the connection of artworks in a narrative encouraged participants to further investigate and interpret what they have read or observed about the artwork. It also lowered the entry bar of engagement with the app, since the audience is familiarised with other more static storytelling approaches (such as audio guides). The process of thinking about and rediscovering the artworks from a different viewpoint initiated a process of a re-familiarisation with the collection, that is fully in line with the sustainability aspects raised at the beginning of this section. For some of them this process allowed them to scratch the surface of the network of links between creators (artists), places and events depicted in the paintings of the collection; P11 "it stopped me and made me think about the fabrics, and because I had fabrics in mind I was looking at those aspects of the painting too, I think more that I haven't before. These are paintings I walk past every day", P09 "so I was reading and then looking at the painting and I found interesting the description because I am familiar with this type of iconography but I found out interesting things".

\subsection{Sustainability in Small Venues}

As one representative of the thousands of small European museums that face significant sustainability issues, the CrossCult project ran one pilot at the Archaeological Museum of Tripolis, in Greece. This museum receives very low numbers of visitors, owing to the fact that it is far from the main tourist destinations of the country, that it hosts items that are not known to the public and that it follows an old-fashioned approach in exhibiting items, with minimum information next to each exhibit and no digital presence. The fact that the museum fails to raise interest among the locals represents an additional flaw.

The CrossCult consortium addressed the question of whether technology-powered storytelling could allow such venues to enrich the experience they provide to the visitors, in the belief that the sustainability of visitor inflow (and the very viability of small museums) depends on the intelligent combination of content and technology to attract visitors. Following Falk and Dierking observations, we created a set of web and mobile apps aiming to start interactions with potential visitors before they even bothered to search the Archaeological Museum of Tripolis on a map, to fill in their visits with thought-provoking content once they were there, and to keep the reflection going on social networks afterwards.

Before the visit, the potential visitor could play specially-designed games, which served both to gain online presence and to create a user profile, identifying specific visitor interests and needs to be supported during the actual museum visit. The games were connected to the museum content and the narratives that could be explored during the visit, thus introducing specific topics. User testing revealed that the games were indeed very effective accomplishing both targets: Advertisement and 
profiling. In particular and in regards to profiling the implemented games were successful in predicting participants' personality styles in $88 \%$ of the time (comparisons to actual psychometric tests), which is an invaluable input to pre-select the topics that they could be most interested in from among the many narratives that we created $[15,16]$.

Being yet another small archaeological museum in the periphery in Greece, the stories created by the CrossCult historians to be delivered during the visits went beyond the expected and provided a non-typical experience, focusing on social aspects of life in Antiquity. In the creative process, we roughly followed Lambert's model for digital storytelling [17,18], with several rounds of selecting focal points from among the physical museum objects, finding appropriate visual material (also from external sources), and enhancing with personal elements and emotions.

According to the museum personnel and their director, focusing on such topics as women's lives in Antiquity and their role in society, could attract new visitors and make the museum content more appropriate for different kinds of visitors. The connections between the ancient society and the current one emerged through the narratives and provided plenty of reflection points. With the app providing food for thought, it came as no surprise in expert user tests that the duration of the visits can increase significantly in comparison with what happened in the original setting, that the visitors would simply wander inside the venue for a few minutes and go away with nothing but unconnected, shallow bits of information. Taking as reference the figures that an average museum visit lasts around $30 \mathrm{~min}$, and the average time spent in front of exhibits is around $30 \mathrm{~s}$ [19], with the designed narratives we increased the overall duration to $40-45 \mathrm{~min}$ and the time in front of selected exhibits to $2-5 \mathrm{~min}$, which are clear indicators of engagement and learning. Those 40-45 min were indeed our target during the creation of the narratives, as longer time would cause museum fatigue $[20,21]$.

The CrossCult pilot for the Archaeological Museum of Tripolis was evaluated different types throughout the project regarding different aspects (e.g., technical, content, experience). There were in total seven data collection studies but for the purposes of the current work we will use quotes from Study 5 (focusing on social reflections of participants) and Study 7 (focusing on individual reflections of visitors). Both studies used the snowball method of recruiting participants, via the researchers' professional networks. The participants were all from the general public, not museum experts. S5 took place in December 2017 with 36 participants (16 males and 20 females, ages ranging from 20 to 55) [13]. After visiting the museum, S5 participants were asked to participate in a social media discussion regarding certain aspects of their experience on one of the museum topics: Appearance of women today and in antiquity. S7 took place in October 2018 with seven volunteers of which there were four female with ages ranging from 40 to 69 (artist, architect, midwife, housewife) and three males with ages ranging from 44 to 76 (medical doctor, film director, private sector employee). The think aloud protocol was used to capture participants' thoughts and experience, as they visited the museum.

User testing also showed that the visitors actively engaged with the digital content and they went beyond simply memorising facts to higher cognitive levels, such as reflection about historical and social phenomena. There were clear signs of reflective processes of app evaluation participants. For example, one user reflected upon the practices of arranged marriages in antiquity and mentioned: S7_P1 "That is very young that they got married... that must be difficult for a teenager...very young girl", following with comparisons of such practices around the world in today's societies and his personal feelings about the issue. Another user evaluated the experience she just had with the app and concluded: S7_P2 "Also allows the visitor to clarify certain things to make him think of issues he had not thought about previously". Such increased reflection processes can be further linked with the quality of the visitor experience and thus the sustainability of visitor numbers in the venue [22,23]. Moreover, visitors reported increased curiosity (e.g., S7_P3 “I would like to know who educated the children inside the house... the parents, their environment, teachers?") and many mentioned that they would look into certain aspects more, even if fewer engaged in further exploration and actively explored the extra material available in the app (e.g., links to the literature sources, relevant games, documentaries and press articles). In any case, the triggered curiosity must be seen as a better quality 
of visitor experience [24,25], also linked to venue sustainability [26]. One cultural informatics expert used the app and mentioned that she liked it so much that she (S7_P6) "needed longer time and wanted more stuff".

After the visit, the app users could share their experience in social media, further promoting the venue to their circles of friends. Vivid discussions followed the museum visit where visitors exchanged opinions regarding the app content and the stories presented to them [27]. For example, the 36 people that participated in these social media discussions, discussed for one week issues related to appearance (women's, nudity, appearance as a code, etc). A special discourse analysis revealed that participants reached upper level cognitive processes, like analysis, emotional activation and evaluation of information [13]. Overall from both studies the qualitative analysis showed that the participants engaged in social reflective processes and exchanged opinions, using facts, building arguments, enhancing cultural understanding and reaching conclusions, S5_P1 "It is striking, however, that women were exercising much more than some later epochs of western European history". In many cases, people made comments that show that their empathy increased, since they tried to imagine how people must have felt in past times and different societies. When explicitly asked for feedback about the app, users reported that it did add important value to the museum experience. Some indicative comments follow: S7_P2 "I think that the app is adding value to the museum", S7_P3"this app definitely helps people in understanding how people thought in past societies, how their society was... their way of life, their traditions, their culture", S7_P7"It (the app) helps people to focus their thoughts and get more deeply into the questions... to reflect on your contemporary life".

These findings were corroborated in another CrossCult pilot in which an app was created to let users discover the heritage and history of one archaeological site (the Roman healing spa of Lugo in Spain, the Roman healing spa of Chaves in Portugal, the archaeological site of Montegrotto Terme in Italy, and the sanctuary of Epidaurus in Greece), while highlighting the commonalities and differences with regard to the others [28,29]. Unprecedented levels of engagement, increased duration of the visits and notable reflection processes were observed during the user tests conducted in the four venues, revealing the power of the wider historical and geographical context when it comes to interpreting heritage, as well as the value of cross-border narratives towards the goal of viewing the past as a shared, common experience. This experience also evidenced the potential for reusing entire narratives or their constituent elements, which is key to the feasibility of storytelling approaches, as explained in the next section.

\section{Sustainability of the Narratives}

Storytelling has long been used by $\mathrm{CH}$ institutions as a method of communication and interpretation. Having human guides telling explicit stories to visitors, while guiding them through the collections of the cultural site remains one of the most effective and popular means nowadays [30,31], but it entails significant costs that can not always be afforded. Audio guides came into scene in the 1980s, fostering more individual experiences and shifting the main costs of storytelling from the human resources to the production of the audio assets and the purchase and maintenance of the devices. During the last decade, the widespread adoption of interactive mobile devices with notable computing and networking capabilities, along with the corresponding changes of content consumption models, have led to extensive experimentation with new forms of interactive storytelling in the $\mathrm{CH}$ sector [32-36]: Historical podcasts, YouTube channels of philosophy and art-related videos, video games with a historical background,... all the way to the minimalist extreme represented by the Facebook account "Classical Art Memes", that has grown to 5.4 million followers sharing and commenting on images excerpted from paintings, linked to ongoing events. Accordingly, the CrossCult project sought to experiment with different types of narratives in the pilots.

Anyways, now that the cost of the devices has been largely transferred to the visitors, the sustainability of technology-powered storytelling depends on effectively supporting the creative and curatorial processes needed to develop experiences that are attractive, engaging and factual. 
Whereas the old audio guides delivered one only narrative-with recordings in multiple languages-to all the visitors, nowadays it is common to offer a menu of choices, multiple paths, driven by more or less complex interactions, and all sorts of visual content, from pictures to immersive 3D environments. Valtolina [37] provided an overview of software tools that aim to facilitate the work, coming to the conclusion that this is a niche market still at an incipient stage, and that it is necessary to develop further the capability to involve a variety of users groups with different backgrounds. In the meantime, researchers keep devising new models, algorithms and artificial intelligence techniques that may be integrated in those tools, e.g., to navigate large online knowledge bases in search for possible associations among artworks, historical events, locations or people that could be turned into interesting stories [8], to automatically retrieve multimedia contents that may be used to illustrate whichever topics [38,39], or to allow museum objects to self-organise and cooperate with other exhibits in order to make comprehensible stories [7]. All in all, the state of the art is such that museum curators and other participants can be given valuable aids in the creative processes of creating stories, but it does not seem feasible (or even desirable) to automate the whole tasks end-to-end, at least in the medium term [40].

Valtolina's proposed framework for storytelling in $\mathrm{CH}$ emphasised the fact that, when narratives comply with certain structures, they can have elements that may be re-used and re-combined in other settings. For example, if the topics are categorised from the most specific to the broadest ones, then it should be possible to adapt existing materials to get new stories for new venues with little effort and cost. Technology still falls short to help in the characterisation of reusable assets, in the hierarchical classification of topics and in the adaptation of existing stories to fit new contexts, among other challenges. However, there exist guidelines, patterns and aids for certain types of narratives, including the ones we assessed in the CrossCult pilot experiments, where we used pre-orchestrated narratives to convey venue messages.

The specific attributes of contemporary mobile technologies significantly affect the content of a narrative and the experience of it [41]. In line with Marshall McLuhan's famous adage that 'the medium is the message', the medium will often impact the way a narrative is told, distributed, and experienced [42]. The CrossCult platform provided a content management system for curating digital and dynamic $\mathrm{CH}$ stories, which takes into account the paintings change of location; the system allows curators and experts to create thematic narratives while their content is dynamically filtered by the CrossCult app to show only paintings that are currently on display. The beta version, connected to the back-end of the NG, has been used to create the stories related to the paintings or artists of the NG Collection. With the essential contribution of humanities experts, CrossCult developed a narrative strategies that allowed their sustainability even after the end of the project.

We conceptualised a model for the structure of the narratives, which would enrich the personalised and context-aware experiences of the CrossCult app (the model is available at the project's deliverables D2.4. Refined digital cultural resource data and data structure and D2.5. Upper-level cultural heritage data structure and ontology, both publicly available at https://www.crosscult.eu/en/resources / deliverables/). One of the structures that we proposed is recursive, meaning that a story can be composed of many elements. These elements acted as containers for carrying the range of additional pieces of information that contribute to the overall narrative and connect the narrative to a physical object. For example, a sculpture of an ancient woman connected to the topic "daily life" was not simply accompanied by a single digital image of that artefact but also by a short video describing the daily life of a woman in ancient Greece, an additional image of a similar sculpture dated to the Roman times, a piece of narrative about motherhood in Antiquity, an audio serving as an initial trigger prior to engaging with the item itself, etc. This model allows for the creation of reusable multi-hierarchical narrative structures and elements that may re-combined into numerous variation presented in Figure 2. Specifically, we used it to produce 9 complete stories for the NG CrossCult app, each one containing 5 to 7 paintings. An illustration of this model with NG paintings that could also point to and connect with the other $\mathrm{CH}$ venues of the project is discussed later on in this section. 


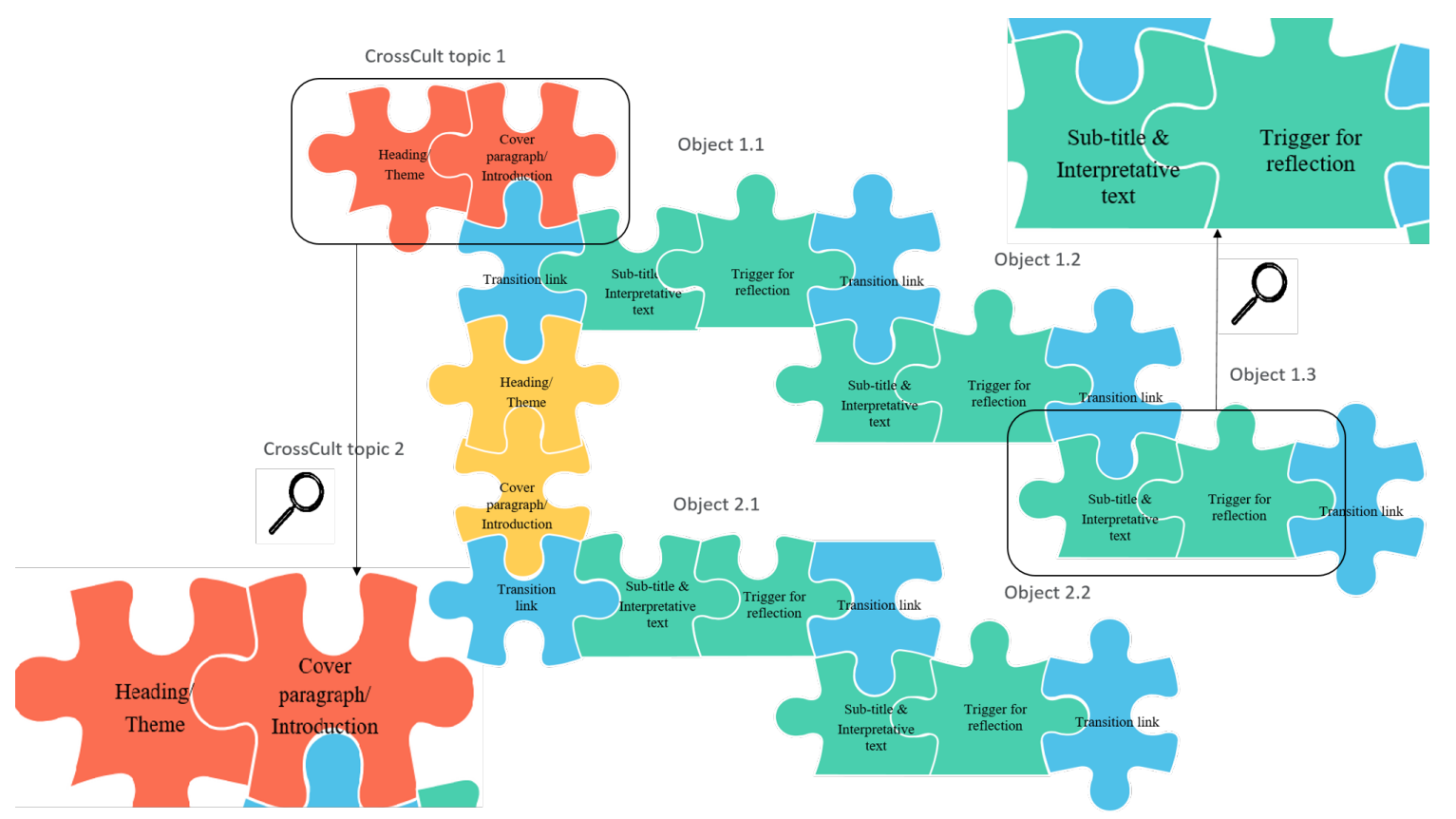

Figure 2. This Figure presents an illustration of the CrossCult stories model and its recursive structure: (a) Each block (painting, text, transition link) in this sequence (objects 1.1, 1.2, 2.1, 2.2) describes one aspect of the related painting. (b) Each sub-unit (see the magnified puzzle pieces on the top right-hand side corner, subtitle and interpretative text and trigger for reflection) provides a highlight. (c) All sub-units (up to 7 in our case) present a story (CrossCult topic 1) that connects objects under a specific theme, the interpretive narrative (heading theme, cover paragraph/introduction, (see the magnified puzzle pieces on the bottom left-hand side corner).

The interpretive design of the narratives communicates cultural values by connecting the tangible form with the intangible meaning within the limitations of the human processing time: 1 to $2 \mathrm{~min}$ assigned per each interpretive unit (individual text per painting, up to 200-250 words on average). In terms of the writing style, the message conveyed is concrete: The use of the passive voice is avoided, while the present tense is dominating the scene. Written language is straight-to-the-point and as expressive as possible, while technical terms are strictly avoided and explained. The purpose of the interpretive text is to assist the reader to extract essential elements related to the scene or the subject being depicted in the painting and it concludes with questions that act as triggers for the reader to reflect on the information presented. These blocks of text do not need to be read in a particular order, which makes the structure flexible enough to accommodate changes. Currently, all the produced content for the 9 stories has been added to the NG Collection management system and is also in use at the NG website (adapted for the in-depth description of the painting-see https://www. nationalgallery.org.uk/paintings/jan-steen-a-peasant-family-at-meal-time-grace-before-meat).

For the pilot experiment connecting the Roman healing spas of Lugo [43] and Chaves [44], the thermomineral archaeological site of Montegrotto Terme [45-48] and the sanctuary of Epidaurus [49,50], we created an app that presents the users with successive bits of a story that describes aspects of life in Roman times. Starting from the phenomenon of healing waters, that was attested both in ancient Greek society and in the Roman Empire, we selected some contexts in which the waters, curative and sacred, played the main role in social dynamics; then, we wrote a story in five episodes that intended to highlight the most important archaeological aspects of each venue with an accessible language and fostering gradual discovery of the ancient settlements and their natural resources, step by step. Thus, the users can learn about chronology and location, the importance of water to human settlements, the use of thermal spas in Roman Age, the relationship between health and cult in that era, the pilgrimage routes enabled by the Roman roads, and the culture reflected in buildings and statues. It was found in the first rounds of user testing that the potential to trigger 
reflection depends heavily on linking the story to observations of the particular site that the user is visiting; a generic, one-size-fits-all narrative would simply not do. Therefore, the overall concept had to be adapted to the particular context of each venue. Fortunately, this could be done with relatively little effort once the Humanities experts had agreed on the core messages and written the first text version. Table 1 below compares, side by side, the text of the first episode of the story presented to people who visit the healing spa of Lugo and those who visit the healing spa of Chaves (in italics, the parts of the text that are venue and object specific).

Table 1. Side-by-side comparison of a passage of the narratives used in a sample of multi-venue storytelling.

Two travellers who came from the Roman city of Brigantium by via XX were attacked on their horses by aggressive dogs. They managed to escape but with some injuries. One of the travellers was wounded in the right leg while the horses had several cuts and bites from the dogs. They continued travelling slowly but they were exhausted, so, as it was late, they decided to spend the night there settling by the river and getting some comfort near the water.

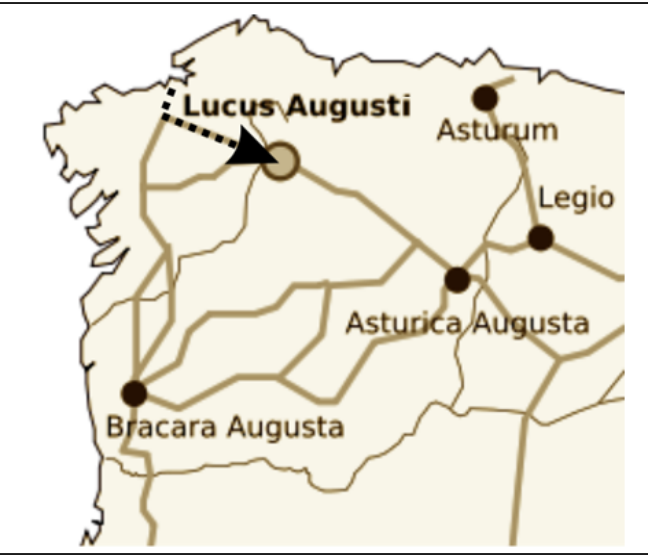

The following morning, the travellers couldn't find the horses: Where had they gone? The friends were desperate! How could they arrive on foot to Asturica Augusta? After a few minutes of stress, they decided to continue their trip looking for their horses.

During their trip they met people: Merchants with their products, men and women on litters with slaves, soldiers, but in particular ill people on charts or walking with crutches. Most of them were going to a settlement that appeared on the horizon: A long bridge spread across the river, and following it, on top of the hill, they could see the walls and towers of a city. In fact, they had reached the Roman city of Lucus Augusti!
Two travellers who came from the Roman city of Bracara Augusta by via XVII were attacked on their horses by aggressive dogs. They managed to escape but with some injuries. One of the travellers was wounded in the right leg while the horses had several cuts and bites from the dogs. They continued travelling slowly but they were exhausted, so, as it was late, they decided to spend the night there settling by the river and getting some comfort near the water.

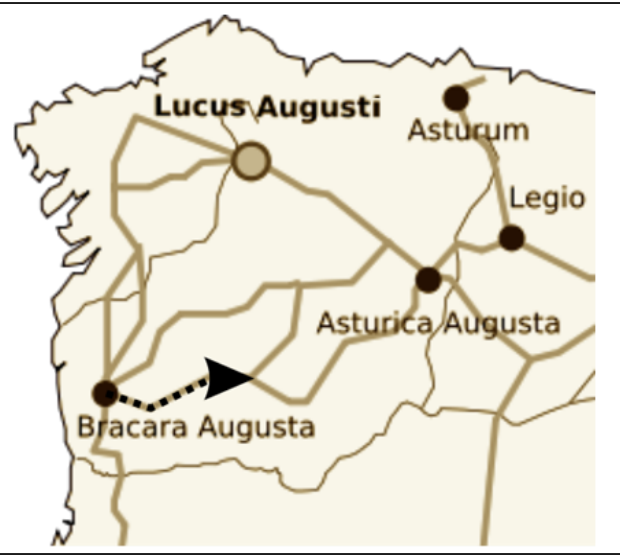

The following morning, the travellers couldn't find the horses: Where had they gone? The friends were desperate! How could they arrive on foot to Asturica Augusta? After a few minutes of stress, they decided to continue their trip looking for their horses.

During their trip they met people: Merchants with their products, men and women on litters with slaves, soldiers, but in particular ill people on charts or walking with crutches. Most of them were going to a settlement that appeared on the horizon: A long bridge spread across the river, and following it, they could see the buildings of a town. In fact, they had reached the Roman city of Aquae Flaviae! 
Table 1. Cont.

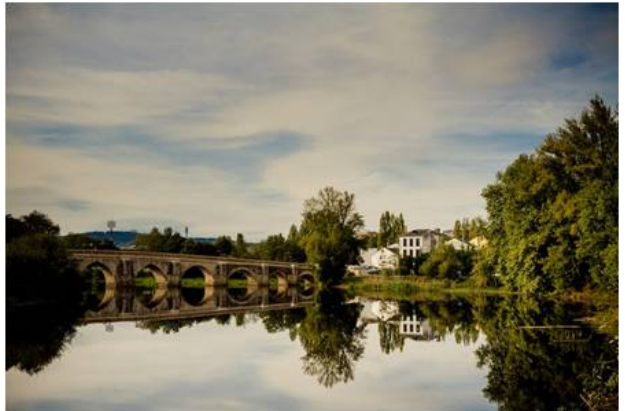

Photograph: Balneario Romano de Lugo

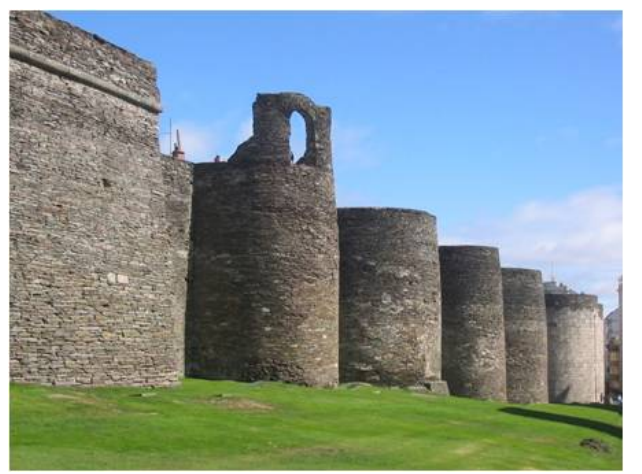

Close to the river, beside a rock, they could see their horses using the backwater of a big building. Gods! They were safe! Where they were, the water seemed something 'magic': There were some channels with really hot water, as vapours came up, and the air smelled of sulphur. Moving close to the horses, the boys saw that the wounded paws were practically healed: A miracle of a deity, they thought immediately! However, they understood that in that place there were thermo-mineral sources and as Roman medicine taught, the sulphurous waters can cure the wounds. So the friends realised that the horses had instinctively gone to the mineral springs to find a natural cure and they decided to have a time there. After many hours and thanks to the use of these waters, the wounded leg looked better.
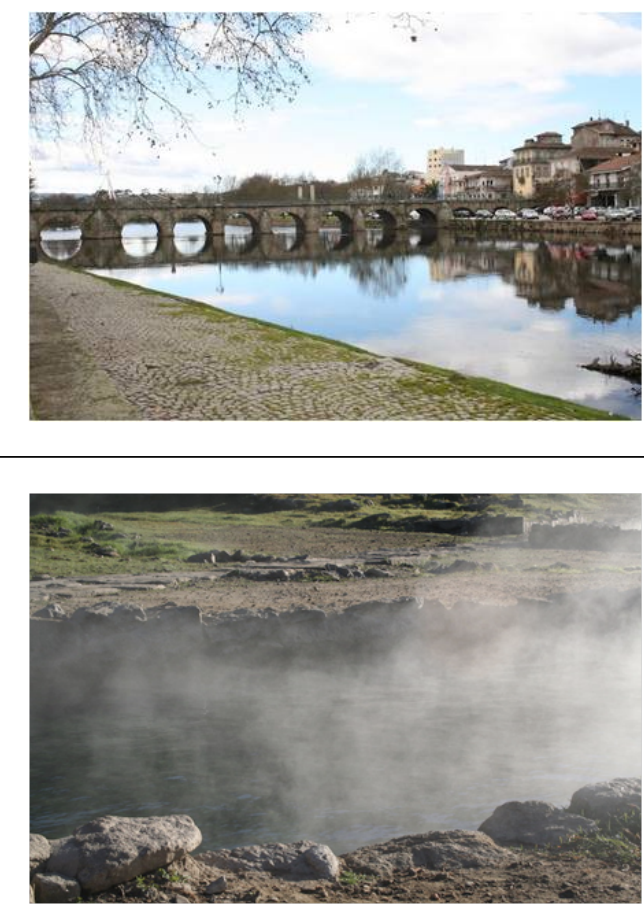

Close to the river, beside a rock, they could see their horses using the backwater of a big building. Gods! They were safe! Where they were, the water seemed something 'magic': There were some channels with really hot water, as vapours came up, and the air smelled of sulphur. Moving close to the horses, the boys saw that the wounded paws were practically healed: A miracle of a deity, they thought immediately! However, they understood that in that place there were thermo-mineral sources and as Roman medicine taught, the sulphurous waters can cure the wounds. So the friends realised that the horses had instinctively gone to the mineral springs to find a natural cure and they decided to have a time there. After many hours and thanks to the use of these waters, the wounded leg looked better.

By reading this bit of story (and looking at the accompanying pictures), the app user becomes acquainted with important elements like the natural and built elements of the ancient landscape, the experience of healing, the presence of deities, some hints of 'scientific' knowledge many centuries ago, people, types of transport, etc. This triggers processes at several cognitive levels: Understanding, application (connections to contemporary practices of thermomineral treatment), analysis (different reasons for healing), evaluation (appropriateness of the treatments) [13]. Caring for all such phenomena in only one go of the creative and curatorial efforts made the development of the app much more cost-effective than having to work separately for each venue. Besides, with the outputs properly 
annotated and kept in a common repository (more about this in Section 4), it is easy to extend the app to cover more than the four original venues: The personnel in charge of the adaptation simply has to revise some passages of text and provide new pictures, in order to get an up-and-running experience with a story that deals with certain concepts and has been proved to work well.

Similarly, the more than 70 narratives created for the Archaeological Museum of Tripolis involved both venue-specific and venue-independent elements, allowing them to be reused in other settings: Straightaway, in tens of small and medium-sized museums all over Greece, and with some more editing (and adopting a more abstract or comparative focus) in many others worldwide. The narratives for the Archaeological Museum of Tripolis were presented to the visitors in the form of videos. Subtitles were also available for people with hearing impairments. The text in Table 2, although written for the Archaeological Museum of Tripolis and the specific object shown in Figure 3, is one clear example (in italics, the parts that are venue- and object-specific, to be removed or replaced for other contexts). The same narrative can be used in different museums where images of ancient Greek girls and women appear, like in the ones in Figure 4. Likewise, elements from other narratives that revolve around the rich Greek mythology may be re-used with a cross-border perspective to reflect on comparisons with myths coined in the places of origin of the museum visitors (e.g., comparing creation myths around the world). Thus, by generalising reuse, small venues would increase their sustainability prospects, providing meaningful experiences to the visitors with reduced cost of producing content.

Table 2. Sample text from a narrative written for the Archaeological Museum of Tripolis, highlighting text that may be easily reused in other settings.

Archaeologists know that this is a young girl. While the head is not surviving, her clothes reveal
her age. Young girls in ancient Greece were usually wearing a long dress all the way to their feet
which also had an upper belt, attached to the body right under the breast. On your screen
(see Figure 5a) you can access images of fine examples of statues of young girls from other
museums. Observe this young girl and compare it with the image of an older woman you can
access on your screen (see Figure 5b). Older women were wearing more complicated
clothes. For example, they had a himation, a mantle or a wrap, which they wore over their chiton,
which was their dress and if they were married they also half covered their hair with a veil, like the
one shown in the photo. In this room, you can see examples of older women's appearance and you
can compare it to the one of the young girl.

Image removed, due to Greek IPR Law that does not allow images or representations of archaeological objects housed in Greek museums to be published under an open license. We believe that this law, increases the un-sustainability of Greek venues and does not offer a realistic tackling of IPR issues in cultural heritage in the era of social media and mobile technologies. Instead of obtaining the required license, the image was removed, but the ones showing similar ancient Greek items from museums around the world are presented here. since these institutions allow the use of the images.

Figure 3. Museum item from the Archaeological Museum of Tripolis. Headless statuette of a young girl. She bears a chiton reaching to the feet with an upper belt. The garment is held onto the chest with straps. She holds a bird in her left hand, while she leans on a stele with her right hand (she leans on a small pillar). Material: Marble. Found in the Bouleuterion of Mantinea. Hellenistic era work (4th-3rd century BC). Dimensions: Height $0.65 \mathrm{~m}$.

The cross-border perspectives, in particular, may be applied to increase the visibility of the small and medium-sized venues, through references from the larger ones. The latter can deliver even richer information linked to their exhibits (for example, by pointing to paintings that share topics and style with one that really catches the visitor's attention) while the formerly suddenly appear on the map to the eyes of tens or hundreds of potential visitors. This can be done at practically no cost, but the impact on the figures of the small museums can be significant: For example, if only 1 in every 100 visitors to the NG in London got to learn that some interesting cultural items can be found in the 
Archaeological Museum of Tripolis, and only 1 out of 100 of those people eventually made a trip to the Peloponnese (not necessarily for that purpose, of course), then this venue would experience a huge increase in its number of visits. The technological infrastructure is not there yet to support and track these promotion mechanisms, but it can be said that many of the technical challenges have already been dealt with [51]. In addition, the narratives created for the Archaeological Museum of Tripolis also connect the museum items with the places that they were originally found (i.e. archaeological settlements, excavation sites of the Arcadia prefecture), thus connecting the museum with the different archaeological locations. This strategy not only shows the locations of the items (augmented reality and maps were used) but also increases the sustainability of the archaeological sites, since it promotes further visits (all sites supported with augmented reality and maps are within one hour drive from the museum). Thus, the museum becomes a central point in the exploration of the area around it.
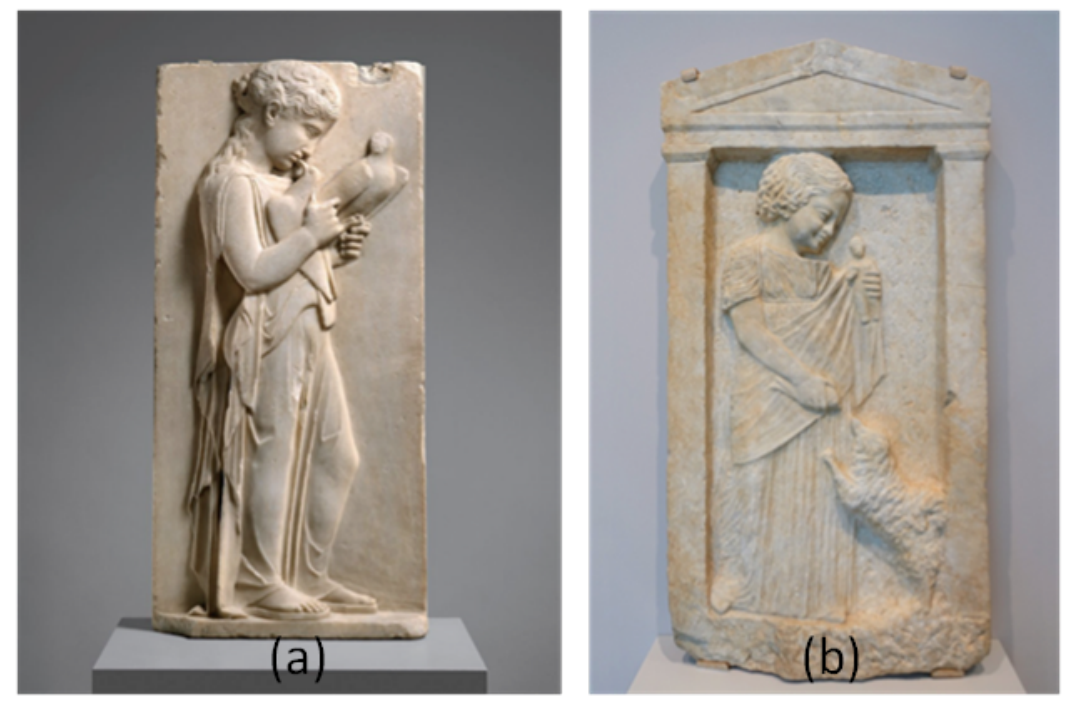

Figure 4. (a) The image on the left hand side is a marble grave stele of a little girl ca. 450-440 BC from the MET, available from https:/ / www.metmuseum.org/art/collection/search/252890. (b) The image on the right hand side is a grave stele of a young girl 'Melisto', Greek, Attic, ca. 340 BC, marble, probably from Sounion-Arthur M. Sackler Museum, Harvard University.

The nine created narratives for the National Gallery CrossCult app (Titles: 'Contemporary Style-Fashion', 'Death', 'Monsters and Demons', 'Battles and Commanders', 'Warfare', 'Migration', 'Water', 'Women's Lives', 'Women artists and famous women') aimed at presenting essential elements related to the scenes or the subject being depicted in the pre-selected paintings, whilst making connections to the other three participating $\mathrm{CH}$ venues at the theme level. In collaboration with the authors and editors of the Collections Information Project (http:/ / network.icom.museum/cidoc/ blog/rupert-shepherd/), who were overseen by the NG curators, we delivered carefully-chosen stories under the broader umbrella-terms 'Social Connections', 'Materials and Techniques', 'Historical Events', pinned to traversal and crosscutting themes "narrated" by the other CrossCult participating $\mathrm{CH}$ venues, such as 'Daily life', 'Appearance' or 'Mortality'. Table 3 shows examples of how the narratives presented to the visitors of the NG in London were connected to the Archaeological Museum of Tripolis on a theme level with the potential to link to and reference specific items of the archaeological collection under the same theme (in italics, the parts that show theme-based connections, between customised narratives to the $\mathrm{CH}$ venues of the National Gallery and the Archaeological Museum of Tripolis, that could be further expanded to make connections between the "participating" in the story items of their collections). 

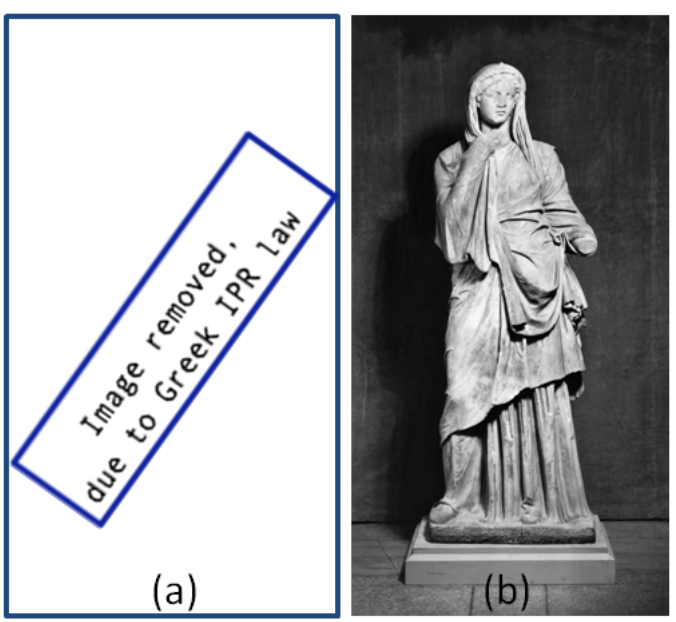

Figure 5. Images (a) on the left hand side and (b) on the right hand side that are used in the narrative presented in Table 2 and were appearing on the app screen.

Table 3. Examples of how narratives presented to the visitors of the NG in London were connected to the Archaeological Museum of Tripolis.

\begin{tabular}{l} 
CrossCult National Gallery stories \\
\hline Women's Lives \\
\hline Gendered roles, expectations and stereotypes can all be \\
communicated through paintings and many of the \\
works in our collection offer insight into ideas about \\
womanhood at particular points in history.
\end{tabular}

Some genre paintings show women's daily lives in the home and the workplace; other paintings show idealised figures based on classical myth or religious stories.

Follow this trail to discover how women have been represented at different times and places across Europe.

\section{CrossCult narratives from the Archaeological Museum of Tripolis}

Daily life

Ancient Greece is known about the great male philosophers, politicians, warriors and artists. But what about ancient Greek women? Where were they? And what did they do?

Women, especially in Classical Athens, were destined to become good wives and especially good mothers. The ideal of a respectful woman is to be indoors, at least till the end of the 4th century BC.

However, women from lower social classes could work outdoors and even go to the Agora to sell home-made products.

Follow us on a journey inside the Oikos, the family's home, to know about the life of women there.

$$
\text { Contemporary Style and Fashion }
$$

Costume plays an important part in the way we perceive people in portraits and figure paintings. Just as the choices we make about our own clothing speak volumes about ourselves, so too does the clothing chosen by those who sit for their portraits.

Yet while faces often appeal to us in a direct way, the significance of dress can be less obvious to a modern viewer.

Artists also frequently have strong views about what the people who sit for portraits should wear, so an outfit may also say something about the artist as well as the sitter, just as clothes in figure paintings can be used to convey the essence of a person's character.
Appearance

The clothes you are wearing today, did you choose them simply because you liked them or you want to tell something to the world?

Ancient societies also found appearance important and clothes often function as a code between the person and the world.

Archaeologist use items' appearance to understand what this person was and the society he or she belonged to. 
Similarly and vice versa, a sculpture of an ancient woman from the Archaeological Museum of Tripolis connected to the topic 'Daily Life', was not simply accompanied by a single digital image of that artefact but also by a short video describing the daily life of a woman in ancient Greece, an additional image of a similar sculpture dated to the Roman times, a piece of narrative about motherhood in Antiquity, an audio serving as an initial trigger prior to engaging with the item itself, etc. More specifically, some of the narratives presented to the visitor of the Archaeological Museum of Tripolis were enriched with digital material from the NG, increasing digital connections of the museum content and enhancing its collection. For example, when introducing the myth of Artemis and Callisto at the Archaeological Museum of Tripolis regarding a statue of Artemis, the narrative (see Table 4) presented a painting by Titian from the NG Collection (see Figure 6), depicting exactly that topic and related content from the 'Diana and Callisto' Schools Project (see https: //www.nationalgallery.org.uk/learning/teachers-and-schools/diana-and-callisto-schools-project).

Table 4. A sample of enriching narratives presented to visitors of the Archaeological Museum of Tripolis with content from National Gallery London.

Accompanied narrative for object: 3084_arcadia, from the Archaeological Museum of Tripolis, part of the greater topic 'names, animals, myths'

Look at this simple tombstone, between the 1st and the 2nd century AD. Despite its simplicity this particular item is of great importance for Arcadia. It bears the inscription HAIL ARCADIA, in the honor of a deceased woman, who has the same name as this area. But the name Arcadia has its root in mythology. According to the myth, once there was the beautiful daughter of Lycaon, the kind of this area and she was called Callisto, meaning the most beautiful. Callisto was Artemis' nymph and had taken a vow to remain a virgin. But Zeus seduced Callisto and she got pregnant. Artemis soon realized and she became furious, and so did Hera the wife of Zeus. Now the myth is not clear but one of the two goddesses transformed the beautiful girl into a bear. As a bear Callisto gave birth to a son called Arcas. Remember here in Greek bear is called Arctos or Arkouda and the name Arcas and Arcadia come from that. Arcas was separated from his mother, since he could not grow up with an animal. One day he went hunting and he nearly killed his own mother. But Zeus intervened and prevented the murder by placing mother and son amongst the stars, as Ursa Major and Minor, star constellations known as Great and Little Bear. And the myth goes further to explain why these two particular constellations are always visible in the northern hemisphere and they never set. This is because Hera cursed them to never rest.

On your screen you can see a famous painting (see Figure 6) by Titian, housed in the National Gallery in London, picturing the scene in which Artemis discovers Callisto's pregnancy. Imagine how she must have felt. Titian beautifully shows her emotions. This particular painting has been used in educational programs of the National Gallery in London (click here for related content from the Diana and Callisto' Schools Project), to show how myths and art can be relevant to today's students. You can also access a very interesting video on the issue of art, myths and hidden pregnancies, as a part of an educational curriculum for teenagers.

It seems that myths and art can be relevant to our modern lives. Can you think of more examples?

By developing narratives in this way, that provide links to other venues, CrossCult created a network of different size and popularity venues. This interconnectivity of participating venues and institutions is beneficial for all. Not only can smaller venues benefit from their links to large-known ones, but by forming a network of venues and reusable narratives, all parties can gain access to elaborated content. In this light, venues are not simply connected to repositories of digital cultural data, but to ready-to-use content in the form of narratives that can be easily modified and applied in different settings, thus increasing sustainability of all parties involved. Data sustainability is further discussed below. 


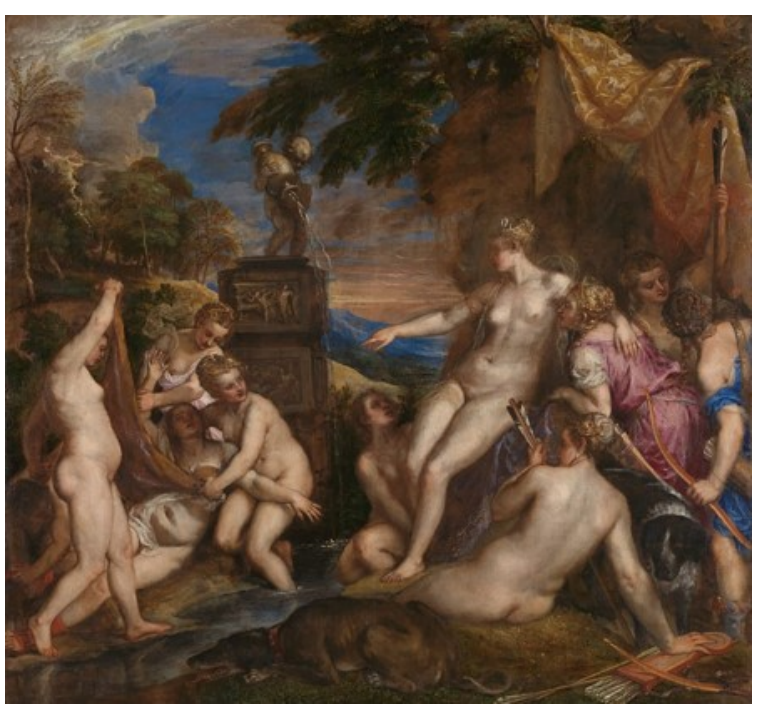

Figure 6. Example of digital material enrichment for the object 3084_arcadia, from the Archaeological Museum of Tripolis. The Image of the painting Titian (NG6616), Diana and Callisto, 1556-9 @The National Gallery London/The National Galleries of Scotland, was part of the archaeological object accompanied narrative, connecting it to the painting.

\section{Sustainability within the CH Ecosystem: Technology, Actors, and Data}

From the preceding sections, it follows that state-of-the-art Information and Communication Technologies can facilitate many aspects of storytelling, from the identification of reusable narratives or elements thereof, to the search for artworks related to any given topic, or the final presentation of the stories to the potential/actual museum visitors through different media. We have explained how storytelling can contribute to the sustainability within the venues-mainly related to numbers of visitors-and discussed the sustainability of the storytelling itself-mainly related to the content production costs. In our experience, the CrossCult app users were exposed to other groups' cultures, to comment, to advocate, to participate, to reflect, to personalise their $\mathrm{CH}$ experiences, supported by a technological system (the CrossCult Platform) that functioned as "brick ties", allowing both innovation and the $\mathrm{CH}$ ecosystem-its users (reflective societies and museum audiences) and stakeholders $(\mathrm{CH}$ venues) - to interact smoothly. Now the questions must be tackled of whether the technology itself can be sustainable, as there may be significant hurdles regarding its adoption and success, whether people related emerged approaches such as the Living Lab or the 'Galleries, Libraries, Archives and Museums' (GLAM) Labs are supportive and sustainable enough to facilitate $\mathrm{CH}$ workforce to make the digital shift happen and finally whether current data flow processes and aggregation of $\mathrm{CH}$ data across a variety of European institutions is a supportive and the most sustainable model for $\mathrm{CH}$ institutions to move forward.

\subsection{Sustainability of Technology}

The first thoughts have to do with openness, covering the following elements (among others):

- The openness of the software tools offered to the Humanities experts to curate digitised $\mathrm{CH}$ assets and to create narratives.

- The openness of the software systems that support platforms of ICT services for Digital Humanities.

- The openness of the digitised $\mathrm{CH}$ archives from which the materials displayed by the narratives are retrieved.

- The openness of the standards and reference models that underpin the archives where the aforementioned assets are kept.

- The openness of the models adopted by many journals that publish the latest advances in DH research. 
As explained in [52], the principles of open source development have not only been massively adopted in the software world, but they have also extended into many other realms, defining how people interact and collaborate beyond the context of computers and mobile consumer devices. The domains of $\mathrm{CH}$ and $\mathrm{DH}$ are no exceptions. The whole set of software systems offered by the Apache Foundation, Wikipedia and Europeana, Open Linked Data resources, Creative Commons licenses, open publishing and, in many cases, crowdsourcing and crowdfunding, share the vision that information should be as freely and publicly accessible as possible. Besides, years of experience have shown that distributed modes of collaboration can be highly effective. The CrossCult platform itself was built on top of this spirit, and as shown in [53] most of the background systems it builds on are open source, just like the foreground software created during the project will be.

However, as pointed out in a recent report on the state of open source [54,55], there is a growing concern about how many projects that may be considered essential infrastructure can sustain themselves indefinitely. Eghbal talks about a "free rider problem", meaning that "resources are offered for free, and everybody (whether individual developer or large software company) uses them, so nobody is incentivised to contribute back, figuring that somebody else will step in." Crichton explains that this problem "has led to a brittle ecosystem, just as open source software reached the zenith of its influence", highlighting examples like OpenSSL- the library that encrypts most of the communications on the web-being a project used in billions of installations, but maintained by a very small team of individuals (only one of them working on it full-time). Those human resources represent crucial weak spots to the software industry, which in the particular realm of DH could be soothed-at least, to a significant extent- through public investment.

This niche area of employment will require highly-specialised profiles in $\mathrm{DH}$, which are not particularly furnished by higher education institutions anywhere around the world (e.g., the list of Universities or Colleges compiled by the European Association for Digital Humanities (EADH) counts as few as 20 entries, see https: / / eadh.org/education/digital-humanities-centres). James O'Sullivan even wonders about what the DH people should be exactly: "A scholar, a domain-specific expert who has advanced computational expertise, or a community builder whose scholarly expertise is less important than the ability to engage others?" [56]. The experience of the CrossCult project shows that the three facets are desirable in bridging the gap between Humanities and Technology experts, because it was challenging to get people from the two different realms to understand one another, and that understanding should not be reached with detriment to the goals of the joint projects. In this particular project, this was achieved as a result of team effort, making sure that technologies and designs were agreed by the whole consortium (not just the tech partners), that acceptance of the technology was based on the users involved, and that human-friendly designs would be promoted rather than technological complexity for complexity's sake. One single person who had that knowledge beforehand would have saved lots of time and boosted the project outcomes. "Ideally", O'Sullivan says, "the DH person would be all those things, a glorious amalgam that can single-handedly secure funding, execute the day-to-day administration of all that precious capacity, lead a team of humanities scholars and software developers, and maintain their own reputation as an international scholar." Again, the sustainability of the technology seems compromised by whether such paragons may be abundant or exist at all. What today is feasible and cost-effective in limited settings, therefore, may not be so easy to scale up. Thus, sustainability of technology in Digital Heritage seems to require a paradigm shift, implying that expertise is not adequate in the individual level and should be built in the group level.

\subsection{Sustainability of Actors}

Our thread of thinking naturally leads us to human networks and how the $\mathrm{CH}$ community is supported to make the transition to the digital realm happen. $\mathrm{CH}$ institutions are champions in building collaborative infrastructures on a regional, national, European and International level. The urgent need of people in $\mathrm{CH}$ institutions "to innovate, feel empowered, trusted, tolerated and 
investeworthy by thinking out of the box" (Dr Georgios Papaioannou, University College London in Qatar and Ionian University, Corfu, Greece, quote available at https://glamlabs.io/), was highlighted in various outputs of Innovation EU projects calls (https: / cordis.europa.eu/programme/rcn/664455/ en). At the same time national $\mathrm{CH}$ institutions attempt to define their digital strategy (for example https:/ / www.nationalgallery.org.uk/media/25328/strategic-plan_2018-2023.pdf) "to reflect a more digital world", whilst building on the research capabilities of their personnel, who is an intellectual leader in their respective fields of expertise.

The International GLAM Labs Community (https://glamlabs.io/), a bottom up created initiative, born in 2018 at an event on global 'Library Labs' held by the British Library, was attended by over 70 people from 43 institutions and 20 countries and followed up by a second global Labs meeting at the Royal Danish Library in Copenhagen in March 2019. The community has now grown to 250 people, from more than 60 institutions, in over 30 countries and has also produced a how-to guide "for cultural institution leaders looking to understand why their organisation might need a GLAM Lab, and also for those workers who are making the case for one" (Seb Chan, Chief Experience Officer, ACMI, Melbourne, quote available at https:/ / glamlabs.io/books/open-a-glam-lab/). GLAM labs (for example the Gardens, Libraries and Museums (GLAM) of the University of Oxford https: / / www.glam.ox.ac.uk/digital-strategy, the British Library Labs https:/ / www.bl.uk/projects/britishlibrary-labs\#) operate at the intersection of digital cultural heritage, innovation, technology and creativity, to benefit organisations, users, society and culture, acting as facilitators of the GLAMs community transition to the digital realm:

- Instrumental for effecting the digital shift in cultural heritage institutions by challenging traditional approaches;

- $\quad$ Bringing institutions, technology, people and communities together through experimental ways of working;

- Based in a variety of cultural heritage institutions including national and state-based libraries, university galleries, libraries, archives and museums.

In CrossCult, we have based our work on the approach proposed by Bergvall-Kåreborn: “A Living Lab is a user-centric innovation milieu to build on everyday practice and research, with an approach that facilitates user influence in open and distributed innovation processes, engaging all relevant partners in real-life contexts and aiming to create sustainable values" $[57,58]$. The CrossCult Living Lab implementation addressed specific areas (IPR and service modelling, stakeholders engagement, experiments) including the sustainability of financing (financial contributions), public-private partnerships, service infrastructure, and the management structure (commitment, responsibilities, influence, promotion and communication of the project's results and outcomes). Our implementation worked on two closely-interconnected levels of governance; at the strategic level, that defines the overall vision and framework of guidelines of the project (involving for example local stakeholders and end-users or regional communities to adopt a common methodological approach towards the defined fields of actions) under the Living Lab Umbrella (for example the Living Lab Steering Board). At an operational level that referred to concretely running field actions (for example specific Living Labs activities, related to the engagement of specific stakeholders, i.e, end-users).

In September 2019, the National Gallery and King's College London jointly launched the 'National Gallery X' (NGX), a collaborative research and development (R\&D) programme that will explore the potential of new technologies for galleries in the future (https:/ / www.nationalgallery.org. uk/about-us/press-and-media/press-releases/national-gallery-and-king-s-college-london-launchnew-research-partnership-national-gallery-x-to-investigate-the-gallery-of-the-future), hosted at a 'physical' sandbox environment, a studio sitting next to the National Gallery (NG) building. The aim of NGX is to allow for experimentation and exploration of technological inventions and how they can be applied to $\mathrm{CH}$ institutions in the future, informing new kinds of cultural experiences over the next decade. Building on expertise, accumulated through internal and external human networks, 
consecutive long term collaborative projects such as Iperion $\mathrm{CH}$ (http://www.iperionch.eu/), CrossCult, and participation in larger research infrastructures such as E-RIHS (http:/ / www.e-rihs.eu/) and SSHOC (https://sshopencloud.eu/), the NG managed to create a sustainable continuum of overlapping $\mathrm{CH}$ research projects, where the $\mathrm{CH}$ ecosystem is sustained through the project outcomes, that feed new questions to engage $\mathrm{CH}$ researchers and future audiences.

\subsection{Sustainability of Data}

In this final subsection, looking back to the $\mathrm{CH}$ datasets that we worked with and the lessons we were taught by the CrossCult experience, we discuss whether current models of $\mathrm{CH}$ data flows to larger aggregators is still a sustainable solution for all types of $\mathrm{CH}$ institutions or whether new paradigms such as aggregation of $\mathrm{CH}$ data across and between $\mathrm{CH}$ European institutions, is gaining more ground as a model to move forward for a more sustainable model within $\mathrm{CH}$ ecosystems. In the CrossCult project, we experimented with both approaches; we demonstrated practical implementations for sharing the $\mathrm{CH}$ datasets to larger collections aggregators such as Europeana but at the same time we also facilitated inter-connections of multi-institutional $\mathrm{CH}$ collections and multiple venues, through the selection of certain organisational patterns, data models, digital storytelling or even specific software [59,60]. We postulate that the sole and one directional aggregation and linking of CH data to larger external repositories, is not sufficient enough to provide meaningful connections between $\mathrm{CH}$ institutions information resources, unless it is reinforced by connections to $\mathrm{CH}$ data modeling standards and interconnections between $\mathrm{CH}$ information resources of the $\mathrm{CH}$ ecosystems themselves.

The first main principle that we followed in the CrossCult Consortium was to adopt, reuse and extend were possible existing exemplary $\mathrm{CH}$ standards followed by the $\mathrm{CH}$ community. In this respect, we used the Conceptual Reference Model (CRM) of the International Council of Museums (ICOM)-International Committee for Documentation (CIDOC), CIDOC-CRM (ISO 21127:2014) to model our data, which provides an object-oriented schema based on real world concepts and events, implementing data harmonisation based on the relationships between things rather than artificial generalisations and fixed field schema. The model has been gaining increased popularity and it is considered to be a major standard in knowledge representation of $\mathrm{CH}$ data. The employment of the CIDOC Conceptual Reference Model enabled us to integrate the disparate datasets of the participating $\mathrm{CH}$ venues and institutions and their metadata under a common semantic layer, driving cross-search and inference capabilities. It also enabled the CrossCult datasets to be sustainable through their linking capabilities with other external $\mathrm{CH}$ datasets following the same standard and mutually benefiting the participating $\mathrm{CH}$ venues and institutions by creating a network of supported venues, increasing visibility and enhancement of their content.

Semantic Web technologies ease access to $\mathrm{CH}$ content by facilitating new ways of engaging with heritage by the general public and experts that go beyond a simple interactive engagement. They provide an intelligent integration of resources via machine readable and human interpretable representations of a domain knowledge (i.e., ontology), enabling retrieval, reasoning, optimal data integration and knowledge reuse of disparate $\mathrm{CH}$ resources. In CrossCult we used semantic web technologies to ensure data backward and forward compatibility, so that the data could potentially be "linked", while the aid of external CH standard vocabularies (i.e., AAT https://www.getty. edu/research/tools/vocabularies/aat/) and multi-hierarchical structures we used for the CrossCult keywords, 'glued' the content of the CrossCult Knowledge base. In terms of data sustainability, this approach facilitated data discovery and content engagement, since the participating $\mathrm{CH}$ venues and institutions gain the same benefits from the linking and interconnections across the collections, as their audiences and visitors do.

At the $\mathrm{CH}$ Institution level, the National Gallery experimented with setting up initially a sandbox API (sandbox is defined here as the concept of having a place where ideas can demonstrate the purpose of functionality) and PID system [61], to demonstrate the potential of reusing and connecting to $\mathrm{CH}$ standards and to provide content for Crosscult. As a result of the work done in the CrossCult and 
IPERION-CH project outputs (http: / / wiki.iperionch.eu/wiki/) organising and mapping the data in the NG beta research API and the extensive testing carried out by Crosscult, the system is already being used in the NG Middleware as part of the collections Information Project and the NG beta API (https: / / data.ng-london.org.uk/) is slowly being replaced by an official institutional beta API, which is still in development (see also the NG object description (61 triples) accessible as an interactive node graph at https:/ / rdf.ng-london.org.uk/modelling).

While our data modelling approach accommodated Interoperability and Reuse, we also made the CrossCult datasets Findable and Accessible, addressing another set of guiding principles towards data sustainability within the CH community, the FAIR Data Principles (see https:/ / www.force11.org/ group / fairgroup/fairprinciples and guidelines on FAIR Data Management in Horizon 2020, available at http:/ / ec.europa.eu/research/participants/data/ref/h2020/grants_manual/hi/oa_pilot/h2020hi-oa-data-mgt_en.pdf) [62]; The project participated in the Open Research Data Pilot, which aimed to make the research data generated by selected Horizon 2020 projects accessible with as few restrictions as possible, while at the same time protecting sensitive data from inappropriate access. The CrossCult datasets and scientific papers are available at the following repositories, Hypatia (http:/ / hypatia.teiath. gr/xmlui/handle/11400/20097 and https:/ /library1.uniwa.gr/en/institutional-depository-hypatia/) and Zenodo (https: / / zenodo.org/search?page=1\&size=20\&q=CrossCult\&all_versions).

So, our last thoughts bring us back to openness; the theme of the last Museums and Tech 2019 conference (https: / / www.museumscomputergroup.org.uk/events/museumstech2019/) was 'Openness: How can museums and other cultural organisations be more open in terms of their collections and processes, is openness always desirable, and what barriers might we have to overcome for truly open digital cultural heritage?'. Delivering his lightning talk, the NG's Collections and Information manager, stated that "Opening up our data already means that we can contribute to the creation of large-scale datasets, keep our collections at the forefront of research, and extend the ways in which users engage with our objects. However, now we've laid the foundations: This is just the beginning." [63], highlighting the fact that the fundamental principles of Access and Openness within the $\mathrm{CH}$ ecosystem, even for a large $\mathrm{CH}$ institution such as the NG are still a long way towards achieving data sustainability.

\section{Sustainability through Reflection}

The CrossCult H2020 project targeted visitors' reflection in multiple levels. Wishing to show the interconnections between locations, people, artefacts and concepts, the project used four pilots cases to show how social and historical phenomena can be re-interpreted. In particular, one of the pilots asked visitors to reflect on aspects of common European history through art, another one on women's place in past and today's societies, a third pilot asked people to reflect on population movements and migration, whereas a fourth one asked people to reflect on healing practices and the therapeutic use of water. These reflection topics were chosen with sustainability criteria, since their generic and contemporary character allows a richer cultural experience and further exploration in other projects.

While reflection in $\mathrm{CH}$ is essential (the European Commission states that "supporting inclusive, innovative and reflective societies is a prerequisite for a sustainable European integration", see External advice and societal engagement: Towards the 2016 and 2017 work programme of 'Inclusive, Innovative and Reflective Societies' of Horizon 2020 available at https: / / ec.europa.eu/programmes/horizon2020/sites/horizon2020/files/External\%20advice\% 20and\%20societal\%20engagement-SC6-2016-2017.pdf), technology does not yet facilitate fully the exploration of such concepts, since constant customisation is needed and more tools are necessary. This implies that stories, narratives and data need to be produced usually ad hoc for the current needs of venues, adding more workload to venue personnel. Our current work provides templates of narratives and guidelines for adaptation, trying to increase sustainability and support venues in the digital transformation. By automating the generation of narratives and the composition of digital $\mathrm{CH}$ resources to deliver meaningful interactive experiences to individuals and groups, we supported 
venue digital strategies (see for example the National Gallery Strategic Plan, available at https:/ / www.nationalgallery.org.uk/media/25328/strategic-plan_2018-2023.pdf2018\T1 \textendash2023) for audience engagement with $\mathrm{CH}$ collections in terms of Learning, Access, Participation. Similarly, the modular logic of the developed technology within CrossCult, also allows its easy adaptation to various other venues. For example, tools like profilers, authoring tools, recommendation engines, visitor tracking tools, etc. can be easily used for the purposes of other venues.

Finally and most importantly, (audience) sustainability is enhanced and empowered through the creation of a network of non-competitive venues that wish to provide their visitors with rich cultural experiences. The cross-visibility and sharing of digital content leads to a win-win situation. In particular, smaller venues can be significantly benefited through their link to large, known ones, since the reflection process can be supported by references to well-known artworks from the large venues.

Author Contributions: Conceptualization: K.K., A.A. and M.L.-N.; data curation: A.D. and J.P.; investigation: K.K., A.A., A.D., S.R.-M., M.B., S.G.-S., J.P., I.L., C.E.J. and M.L.-N.; methodology: A.A., S.R.-M., M.B., S.G.-S. and C.E.J.; project administration: I.L.; resources: S.R.-M., M.B., S.G.-S. and J.P.; software: K.K., A.D., C.E.J. and M.L.-N.; supervision: S.R.-M., M.B. and S.G.-S.; writing-original draft: K.K., A.A., A.D. and M.L.-N.; writing-review and editing: S.R.-M., M.B., S.G.-S. and J.P. All authors have read and agreed to the published version of the manuscript.

Funding: This research was funded by the European Union's Horizon 2020 research and innovation programme under grant agreement No 693150. The authors from the University of Vigo got further support from the European Regional Development Fund (ERDF) and the Galician Regional Government under agreement for funding the AtlantTIC Research Center for Information and Communication Technologies, as well as the Ministerio de Educación y Ciencia (Gobierno de España) research project TIN2017-87604-R.

Acknowledgments: We would like to acknowledge the contribution of the National Gallery Collections and Information project authors, editors, reviewers and the National Gallery curators, in the production of the CrossCult NG narratives.

Conflicts of Interest: The authors declare no conflict of interest.

\section{Abbreviations}

The following abbreviations are used in this manuscript:

$\mathrm{CH}$ Cultural Heritage

DH Digital Humanities

NG National Gallery

ICT Information and Communication Technologies

\section{References}

1. Marstine, J. Routledge Companion to Museum Ethics Redefining Ethics for the Twenty-First Century Museum; Routledge: Abingdon, UK; New York, NY, USA, 2011; p. 276, ISBN 1-280-68258-2.

2. Dümcke, C.; Gnedovsky, M. The Social and Economic Value of Cultural Heritage: Literature Review; EENC: Chapel Hill, NC, USA, 2013.

3. Greffe, X. Concept study on the role of Cultural Heritage as the fourth pillar of Sustainable Development. Venice Sustcult Proj. 2012, 1-73. Available online: http:/ / docplayer.net/24195641-Concept-study-on-the-roleof-cultural-heritage-as-the-fourth-pillar-of-sustainable-development.html (accessed on 22 February 2020).

4. Ecorys; Associates, F. Economic Value of Ireland's Historic Environment; Final report to the Heritage Council; ECORYS: Rotterdam, The Netherlands, 2012; 94p.

5. Young, J.O. The Ethics of Cultural Appropriation; Wiley-Blackwell: Oxford, UK, 2009.

6. Kontiza, K.; Bikakis, A.; Miller, R. Cognitive-Based Visualization of Semantically Structured Cultural Heritage Data. In Proceedings of the 14th International Semantic Web Conference, Bethlehem, PA, USA, 11-15 October 2015.

7. Vassilakis, C.; Poulopoulos, V.; Antoniou, A.; Wallace, M.; Lepouras, G.; López Nores, M. exhiSTORY: Smart exhibits that tell their own stories. Future Gener. Comput. Syst. 2018, 81, 542-556. [CrossRef] 
8. López-Nores, M.; Bravo-Quezada, O.G.; Bassani, M.; Antoniou, A.; Lykourentzou, I.; Jones, C.E.; Kontiza, K.; Gonzalez-Soutelo, S.; Reboreda-Morillo, S.; Naudet, Y.; et al. Technology-Powered Strategies to Rethink the Pedagogy of History and Cultural Heritage through Symmetries and Narratives. Symmetry 2019, 11, 22. [CrossRef]

9. Antoniou, A. Social network profiling for cultural heritage: Combining data from direct and indirect approaches. Soc. Netw. Anal. Min. 2017, 7, 1-11. [CrossRef]

10. Juniarta, N.; Couceiro, M.; Napoli, A.; Raïssi, C. Sequential Pattern Mining using FCA and Pattern Structures for Analyzing Visitor Trajectories in a Museum. CLA 2018, 2018, 231-242.

11. Theodorakopoulos, M.; Papageorgopoulos, N.; Mourti, A.; Antoniou, A.; Wallace, M.; Lepouras, G.; Vassilakis, C.; Platis, N. Personalized Augmented Reality Experiences in Museums using Google Cardboards. In Proceedings of the 12th International Workshop on Semantic and Social Media Adaptation and Personalization, Bratislava, Slovakia, 9-10 July 2017.

12. Falk, J.H.; Dierking, L.D. The Contextual Model of Learning. The Museum Experience Revisited; Routledge: Abingdon, UK, 2012.

13. Jones, C.; Antoniou, A.; López-Nores, M.; Kontiza, K.; Schall, C.; Naudet, Y.; Deladiennée, L. Evaluation and Best Practices Report; CrossCult Deliverable 5.3 Final version; Unpublished work, 2019.

14. Kontiza, K.; Loboda, O.; Deladiennee, L.; Castagnos, S.; Naudet, Y. A Museum App to Trigger Users' Reflection. 2018. Available online: https://pdfs.semanticscholar.org/f63b/ 8016534c129076b5dd89d30eb637dc700047.pdf (accessed on 12 February 2020).

15. Bampatzia, S.; Bourlakos, I.; Antoniou, A.; Vassilakis, C.; Lepouras, G.; Wallace, M. Serious games: valuable tools for cultural heritage. In Proceedings of the International Conference on Games and Learning Alliance, Utrecht, The Netherlands, 5-7 December 2016; Springer: Cham, Switzerland, 2016; pp. 331-341.

16. Antoniou, A. Predicting Cognitive Profiles from a Mini Quiz: A Facebook Game for Cultural Heritage. In Proceedings of the International Conference on Games and Learning Alliance, Palermo, Italy, 5-7 December 2018; Springer: Cham, Switzerland, 2018; pp. 422-425.

17. Lambert, J. Digital Storytelling: Capturing Lives, Creating Community; Routledge: Abingdon, UK, 2013.

18. Dunford, M.; Jenkins, T.E. Digital Storytelling: Form and Content; Springer: Berlin/Heidelberg, Germany, 2017.

19. Falk, J.H. The use of time as a measure of visitor behavior and exhibit effectiveness. Roundtable Rep. 1982, 7, $10-13$.

20. Davey, G. What is museum fatigue. Visit. Stud. Today 2005, 8, 17-21.

21. Falk, J.; Koran, J.; Dierking, L.; Dreblow, L. Predicting Visitor Behaviour. Curator 1985, $28,4$.

22. Weiler, B.; Walker, K. Enhancing the visitor experience: Reconceptualising the tour guide's communicative role. J. Hosp. Tour. Manag. 2014, 21, 90-99. [CrossRef]

23. Cosley, D.; Lewenstein, J.; Herman, A.; Holloway, J.; Baxter, J.; Nomura, S.; Gay, G. ArtLinks:fostering social awareness and reflection in museums. In Proceedings of the SIGCHI Conference on Human Factors in Computing Systems, Florence, Italy, 5-10 April 2008; ACM: New York, NY, USA, 2008; pp. 403-412.

24. Rounds, J. Strategies for the curiosity-driven museum visitor. Curator Mus. J. 2004, 47, 389-412. [CrossRef]

25. Ciolfi, L.; Bannon, L. Designing Interactive Museum Exhibits: Enhancing visitor curiosity through augmented artefacts. In Proceedings of the Eleventh European Conference on Cognitive Ergonomics, Catania, Italy, 8-11 September 2002.

26. Di Pietro, L.; Guglielmetti Mugion, R.; Renzi, M.F.; Toni, M. An audience-centric approach for museums sustainability. Sustainability 2014, 6, 5745-5762. [CrossRef]

27. Poulopoulos, V.; Vassilakis, C.; Antoniou, A.; Lepouras, G.; Theodoropoulos, A.; Wallace, M. The Personality of the Influencers, the Characteristics of Qualitative Discussions and Their Analysis for Recommendations to Cultural Institutions. Heritage 2018, 1, 239-253. [CrossRef]

28. Dahroug, A.; Aborizka, M.; López Nores, M.; Pazos Arias, J. A mobile app to explore cultural and historical associations between Europe and the Arab and the Islamic worlds. In Proceedings of the 12th International Conference on ICT, Society and Human Beings, Porto, Portugal, 16-19 July 2019.

29. Daif, A.; Dahroug, A.; López-Nores, M.; González-Soutelo, S.; Bassani, M.; Antonio, A.; Gil-Solla, A.; Ramos-Cabrer, M.; Pazos-Arias, J.J. A Mobile App to Learn About Cultural and Historical Associations in a Closed Loop with Humanities Experts. Appl. Sci. 2019, 9, 9. [CrossRef]

30. Best, K. Making museum tours better: Understanding what a guided tour really is and what a tour guide really does. Mus. Manag. Curatorship 2012, 27, 35-52. [CrossRef] 
31. Bearman, D.; Geber, K. Transforming cultural heritage institutions through new media. Mus. Manag. Curatorship 2008, 23, 385-399. [CrossRef]

32. Linaza, M.T.; Eskudero, H.; Lamsfus, C.; Marcos, G. An authoring tool for interactive digital storytelling. In Proceedings of the 5th International Conference on Virtual Reality and Archaeology and Intelligent Cultural Heritage (vast'04), Oudenaarde, Belgium, 7-10 December 2004; Chrysanthou, Y., Cain, K., Silberman, N., Niccolucci, F., Eds.; Eurographics Association: Aire-la-Ville, Switzerland, 2004; pp. 203-211. [CrossRef]

33. Lu, F.; Tian, F.; Jiang, Y.; Cao, X.; Luo, W.; Li, G.; Zhang, X.; Dai, G.; Wang, H. Creative and collaborative digital storytelling inspired by cultural heritage. In Proceedings of the SIGCHI Conference on Human Factors in Computing Systems (CHI11), Vancouver, BC, Canada, 7-12 May 2011; ACM: New York, NY, USA, 2011; pp. 1919-1928. [CrossRef]

34. Lombardo, V.; Damiano, R. Storytelling on mobile devices for cultural heritage. New Rev. Hypermedia Multimed. 2012, 18, 11-35. [CrossRef]

35. Shin, J.; Park, H.; Woo, W. Connecting the Dots: Enhancing the Usability of Indexed Multimedia Data for AR Cultural Heritage Applications through Storytelling. In Proceedings of the 15th International Workshop on Content-Based Multimedia Indexing (CBMI), Florence, Italy, 19-21 June 2017; ACM: New York, NY, USA, 2017; p. 6. [CrossRef]

36. Vanoverschelde, F. No Story without a Backstory: The role and importance of the backstory in an augmented reality application for cultural heritage. In Proceedings of the 8th International Workshop on Narrative and Hypertext (NHT19), Hof, Germany, 17 September 2019; ACM: New York, NY, USA, 2019; pp. 1-3. [CrossRef]

37. Valtolina, S. A storytelling-driven framework for cultural heritage dissemination. Data Sci. Eng. 2016, 1, 114-123. [CrossRef]

38. Peters, C.; Braschler, M.; Clough, P. Multilingual Information Retrieval; Springer: Berlin/Heidelberg, Germany, 2012.

39. Tandon, A.; Slomska, A.; Opoku-Boateng, J.; Abbazia, D. Unlocking Sound and Image Heritage. In Proceedings of the International SOIMA Conference, Brussels, Belgium, 3-4 September 2015.

40. Siegman, A. First Words: The World of Automated Storytelling. 2017. Available online: https:// brainworldmagazine.com/first-words-the-world-of-automated-storytelling/ (accessed on 18 February 2020).

41. Hayles, N.K. Print Is Flat Code Is Deep: The Importance of Media-Specific Analysis. Poet. Today 2004, 25, 67-90. [CrossRef]

42. McLuhan, M. Understanding Media; Routledge: London, UK, 1964.

43. Crecente Maseda, M.; González Soutelo, S. (Eds.) 2000 años del Balneario de Lugo: Un Modelo de Activación del Patrimonio Termal; Crecente Asociados: Lugo, Spain, 2016.

44. Carneiro, S. New data from the Roman healing spa of Aquae Flaviae (Chaves, Portugal). In Termalismo Antiguo en Hispania: Un Análisis del Tejido Balneario en éPoca Romana y Tardorromana en la Península Ibérica; Séiquer, G.M., Soutelo, S.G., Eds.; Anejos de Archivo Español de Arqueología 78; CSIC: Madrid, Spain, 2017; pp. 65-94.

45. Bassani, M.; Bressan, M.; Ghedini, F. Aquae Patavinae. Il Termalismo Antico nel Comprensorio Euganeo e in Italia. Atti del I Convegno Nazionale (Padova, 21-22 giugno 2010); Padova University Press: Padova, Italy, 2011; Volume 21, pp. 1-296.

46. Bassani, M.; Bressan, M.; Ghedini, F. Montegrotto Terme e il termalismo in Italia. Aggiornamenti e nuove prospettive di valorizzazione. In Atti del II Convegno Nazionale (Padova, 14-15 giugno 2011); Padova University Press: Padova, Italy, 2012; Volume 26, pp. 1-424.

47. Bassani, M.; Bressan, M.; Ghedini, F. Aquae salutiferae. Il termalismo fra antico e contemporaneo. In Atti del Convegno Internazionale (Montegrotto Terme, 6-8 Settembre 2012); Padova University Press: Padova, Italy, 2013; Volume 29, pp. 1-449.

48. Annibaletto, M.; Bassani, M.; Ghedini, F. Cura, Preghiera e Benessere. Le Stazioni Curative Termominerali Nell'Italia Antica; Padova University Press: Padova, Italy, 2014; Volume 31, pp. 1-336.

49. Kasas, S.; Struckman, R. Important Medical Centres in Antiquity_Epidaurus and Corinth-: When Medicine Was Still Divine; Two Contributions to the Study of Ancient Medicine: (A) Some Medical Treatments in Ancient Corinth, (b) Asklepios in Epidaurus; Editions Kasas: Athens, Greece, 1979. 
50. Lambrinoudakis, V.K. Conservation and research: New evidence on a long-living cult. The sanctuary of Apollo Maleatas and Asklepios at Epidauros. In Excavating Classical Culture. Recent Archaeological Discoveries in Greece; Stamatopoulou, M., Yeroulanou, M., Eds.; BAR INternational Series 1031; Beazley: Oxford, UK, 2002; pp. 213-223.

51. López-Nores, M.; Kuflik, T.; Wallace, M.; Naudet, Y. Preface to the UMUAI special issue on personalized delivery of cultural heritage content-Perspectives on 7 years of progress in the field. User Model. User Adapt. Interact. 2019, 29, 1-7. [CrossRef]

52. Tozzi, C. Free Software and Free Culture: Open Source's Influence on Society; Channel Futures: Pittsford, NY, USA, 2015.

53. Liapis, A.; López-Nores, M.; Gil-Solla, A.; Naudet, Y.; Lykourentzou, I.; Deladiennée, L.; Castagnos, S.; Napoli, A.; Antoniou, A.; Platis, N.; et al. Identification of Technologies and Useful Software. CrossCult Deliverable 3.1. Available online: http://www.crosscult.eu/en/resources/deliverables/ (accessed on 18 February 2020).

54. Eghbal, N. Roads and Bridges: The Unseen Labor Behind Our Digital Infrastructure; Ford Foundation: New York, NY, USA, 2016.

55. Crichton, D. Open Source Sustainability; Tech Crunch: Bay Area, CA, USA, 2018.

56. O'Sullivan, J. We Need to Talk about the Digital Humanities Job; Talking Humanities:New York, NY, USA, 2018.

57. Bergvall-Kareborn, B.; Eriksson, C.I.; Staahlbröst, A.; Svensson, J. A Milieu for Innovation: Defining Living Labs. In Proceedings of the 2nd ISPIM Innovation Symposium, New York, NY, USA, 6-9 Decmber 2009.

58. Bergvall-Kareborn, B.; Stahlbrost, A. Living Lab: An open and citizen-centric approach for innovation. IJIRD 2009, 1, 356-370. [CrossRef]

59. Vlachidis, A.; Bikakis, A.; Kyriaki-Manessi, D.; Triantafyllou, I.; Antoniou, A. The CrossCult Knowledge Base. A Co-inhabitant of Cultural Heritage Ontology and Vocabulary. In Advances in Databases and Information Systems 2017: New Trends in Databases and Information Systems; Springer: Cham, Switzerland, 2017; pp. 353-362.

60. Vlachidis, A.; Bikakis, A.; Kyriaki-Manessi, D.; Triantafyllou, I.; Padfield, J.; Kontiza, K. Semantic Representation and Enrichment of Cultural Heritage Information for Fostering Reinterpretation and Reflection on the European History. In Proceedings of the Digital Cultural Heritage: Final Conference of the Marie Skłodowska-Curie Initial Training Network for Digital Cultural Heritage, ITN-DCH 2017, Olimje, Slovenia, 23-25 May 2017; Ioannides, M., Ed.; Springer: Cham, Switzerland, 2017; pp. 99-103.

61. Padfield, J.; Kontiza, K.; Bikakis, A.; Vlachidis, A. Semantic Representation and Location Provenance of Cultural Heritage Information: The National Gallery Collection in London. Heritage 2019, 2, 648-665. [CrossRef]

62. Wilkinson, M.D.; Dumontier, M.; Aalbersberg, I.J.; Appleton, G.; Axton, M.; Baak, A.; Blomberg, N. The FAIR Guiding Principles for scientific data management and stewardship. Sci. Data 2016, 3, 1-9. [CrossRef] [PubMed]

63. Shepherd, R.; Padfield, J.; Tice, R. Opening Up the National Gallery's Collection Information; Museums+Tech: London, UK, 2019.

(C) 2020 by the authors. Licensee MDPI, Basel, Switzerland. This article is an open access article distributed under the terms and conditions of the Creative Commons Attribution (CC BY) license (http://creativecommons.org/licenses/by/4.0/). 